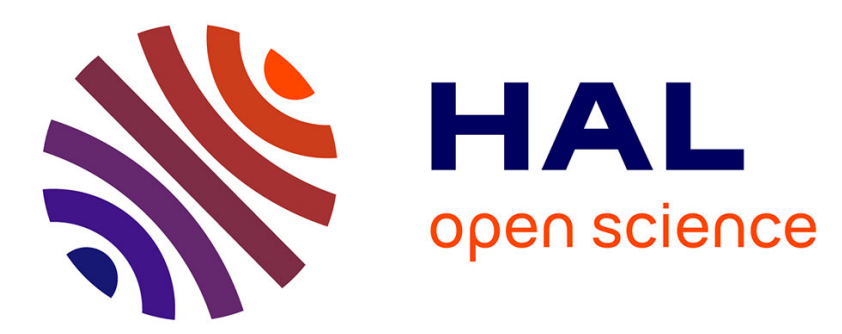

\title{
Renewable electricity producing technologies and metal depletion: A sensitivity analysis using the EROI Florian Fizaine Fizaine, Victor Court
}

\section{To cite this version:}

Florian Fizaine Fizaine, Victor Court. Renewable electricity producing technologies and metal depletion: A sensitivity analysis using the EROI. Ecological Economics, 2015, 110, pp.106-118. 10.1016/j.ecolecon.2014.12.001 . hal-01170989

\section{HAL Id: hal-01170989 \\ https://hal.science/hal-01170989}

Submitted on 15 Dec 2015

HAL is a multi-disciplinary open access archive for the deposit and dissemination of scientific research documents, whether they are published or not. The documents may come from teaching and research institutions in France or abroad, or from public or private research centers.
L'archive ouverte pluridisciplinaire HAL, est destinée au dépôt et à la diffusion de documents scientifiques de niveau recherche, publiés ou non, émanant des établissements d'enseignement et de recherche français ou étrangers, des laboratoires publics ou privés. 
Renewable electricity producing technologies and metal depletion: a sensitivity analysis using the EROI

Corresponding author: Florian FIZAINE

LEDi - Laboratoire d'Économie de Dijon - UMR 6307 - Université de Bourgogne 2 boulevard Gabriel, BP 26611, 21066 DIJON cedex, France

Phone: +33 (0)633663339,

Email: florian.fizaine@gmail.com

Victor COURT

EconomiX - UMR 7235 - Université Paris Ouest, Nanterre - La Défense

200, av. de la République, 92001 Nanterre, France

Email: victor.court@chaireeconomieduclimat.org 


\title{
Renewable electricity producing technologies and metal depletion: a sensitivity analysis using the EROI
}

\author{
Florian FIZAINE ${ }^{1}$ and Victor COURT ${ }^{2}$
}

\begin{abstract}
More and more attention is being paid to renewable technologies because they are seen as a great opportunity to disengage our society from its dependence on fossil fuels. Such flow-based energy resources that rely on solar energy are supposed to lead us toward a sustainable energy future. However, because of their high capital intensity, renewable technologies require large amounts of matter, including both common and rare metals. These metals require energy for their production, and more specifically for their extraction. The energy cost associated with metal extraction is linked to mineral ore grade, meaning that as depletion progresses, energy cost increases. In addition, renewable energy resources deliver less net energy to society compared to fossil fuels, because of their diffuse nature. It is therefore easy to see that a close relationship exists between energy and metals sectors. In this article, we described more precisely this relationship by investigating how the energy requirement associated with metal extraction could impact the energy-return-oninvestment (EROI) of different renewable and nuclear technologies. More precisely, we present a methodology that can be used to calculate the sensitivity of the EROI of a given technology to a specific or to multiple metals ore grade degradation. We found that if considered separately, the qualitative depletion of a given metal has not a significant impact on the EROI of renewable and nuclear technologies, unless its concentration approaches very low grade. However, if all metals are considered together, the EROI of these same technologies could be importantly diminished, especially if they tend to very low concentrations.
\end{abstract}

Key words: EROI, renewable energy, metals, net energy, depletion.

Code JEL: Q3, Q4, Q5.

\footnotetext{
${ }^{1}$ LEDi - Laboratoire d'Économie de Dijon - UMR 6307 - Université de Bourgogne, Email : florian.fizaine@gmail.com

2 EconomiX - UMR 7235 - Université Paris Ouest, Nanterre - La Défense, Email : victor.court@chaireeconomieduclimat.org
} 


\section{Introduction}

Energy is of primary importance for human societies. Indeed, as for any other physical system, our economic system requires the input of high-quality energy that is used to support physical processes and perform actual work, and is then consequently degraded into low-quality energy (heat) (Georgescu-Roegen, 1971; Odum, 1971; Daly, 1985). Many authors have emphasized the fact that fossil fuels have enabled human organizations to take the path of industrialization and then service-oriented society thanks to their abundance, high concentration and associated low energy cost of extraction (Hall and Klitgaard, 2012; Stern and Kander, 2012; Ayres and Voudouris, 2014). Fossil fuels are by definition non-renewable because they represent finite stocks. They are furthermore a source of pollution, with green house gases emissions monopolizing most of the attention. For these different reasons, the resilience of current complex societies is now questioned and the need to operate a transition from fossil to renewable energies ${ }^{3}$ appears obvious and necessary. However, some researchers have already highlighted that renewable technologies rely on various metals like any other infrastructure; and that the requirement of the different sort of metals needed to produce a unit of renewable energy is more intense when compared to fossil fuels. Furthermore, the extraction of metals from deposits, and their concentration in useable forms require energy. Some studies have shown that the energy cost associated with metal production increases as metal concentration in deposit decreases (Hall et al, 1986). We can see that a complex interdependence exists between energy and metals sectors and it is the purpose of this article to further investigate this relation.

In the present paper, we will first give an estimation of the current amount of global energy consumed by the metal sector. Unfortunately, doing the opposite calculation of the amounts of the different metals cornered by the energy sector is quite impossible. Because the energy cost associated with metal extraction is increasing and that many different metals are required in renewable technologies, we will then see that using the energy-return-on-investment (EROI) concept is a useful approach for our topic. We investigate here how the increasing energy cost associated with a specific metal extraction could influence the EROI of different renewable technologies. Then, we have also tested a broader sensitivity of the EROI of these same technologies to all the different metals they require. Finally, we will discuss our methodology, in particular its underlying assumptions, and make some suggestions for further improvements of the kind of analysis we have performed.

\footnotetext{
${ }^{3}$ In this article, renewable technologies refer to renewable electricity production from wind and solar energy (wave and tidal could have been incorporated under this denomination, although lack of data prevent us from studying these nascent means of electricity production); biomass is considered out of our scope of study.
} 


\section{Empirical observations}

\subsection{Interrelation between energy and metal sectors}

Sectors of metal extraction and production represent a significant share of total energy consumption. Rankin (2011) estimated that $10 \%$ of global primary energy production is consumed by the metal sector. Data from the International Energy Agency (2014) and from Norgate and Jahanshahi (2011) give a lower value of approximately 7\%. We performed our own estimation, using data on mean energy cost of metal production (Valero and Botero, 2002; Rankin, 2011; Tharumarajah and Koltun, 2011; Ashby, 2013) and quantities of production (USGS, 2012) for different metals. As can be seen in Table 1, we found as Rankin that at global level the metal sector requires about $10 \%$ of total primary energy consumption. Of course a degree of uncertainty around these data exists for two reasons: unitary energy costs have different year of estimation; and the method of allocation of the joint cost in case of coproduction with other metals may differ from one study to an other.

Table 1 Estimations of the energy cost associated with different metal productions and the entire metal sector. Source: diverse, see table.

\begin{tabular}{|c|c|c|c|c|c|}
\hline Metal & $\begin{array}{c}\text { Energy cost } \\
\text { of } \\
\text { production } \\
(\mathbf{G J} / \mathbf{t})\end{array}$ & Source & $\begin{array}{c}\text { Production in } \\
2012 \text { (USGS, } \\
\text { 2012) }\end{array}$ & $\begin{array}{l}\text { Total energy } \\
\text { cost }(\mathbf{G J})\end{array}$ & $\begin{array}{c}\text { Share of total } \\
\text { energy } \\
\text { consumption } \\
(\%)\end{array}$ \\
\hline Aluminum & 212 & Rankin (2011) & 44400000 & 9391044000 & $1.798 \%$ \\
\hline Antimony & 13 & Valero and Botero (2002) & 180000 & 2412000 & $0.000 \%$ \\
\hline Arsenic & 28 & Valero and Botero (2002) & 46700 & 1307600 & $0.000 \%$ \\
\hline Beryllium & 457.2 & Valero and Botero (2002) & 230 & 105156 & $0.000 \%$ \\
\hline Bismuth & 56.4 & Valero and Botero (2002) & 7600 & 428640 & $0.000 \%$ \\
\hline Cadmium & 110 & $\begin{array}{l}\text { Valero and Botero (2002) } \\
\text { Tharumarajah and Koltun }\end{array}$ & 21800 & 2398000 & $0.000 \%$ \\
\hline Cerium & 354 & $(2011)$ & 27000 & 9563400 & $0.002 \%$ \\
\hline Chromium & 64 & Valero and Botero (2002) & 24000000 & 1538400000 & $0.295 \%$ \\
\hline Cobalt & 322 & Valero and Botero (2002) & 110000 & 35420000 & $0.007 \%$ \\
\hline Copper (hydro) & 64 & Rankin (2011) & 17000000 & 1095820000 & $0.210 \%$ \\
\hline Copper (pyro) & 33 & Rankin (2011) & 17000000 & 561340000 & $0.107 \%$ \\
\hline Gadolinium & 2162 & $\begin{array}{l}\text { Tharumarajah and Koltun } \\
\text { (2011) }\end{array}$ & 5000 & 10812000 & $0.002 \%$ \\
\hline Gallium & 12660 & Valero and Botero (2002) & 200 & 2532000 & $0.000 \%$ \\
\hline Germanium & 2215 & Valero and Botero (2002) & 118 & 261370 & $0.000 \%$ \\
\hline Gold & 68400 & Rankin (2011) & 2700 & 184680000 & $0.035 \%$ \\
\hline Hafnium & 633 & Valero and Botero (2002) & 90 & 56970 & $0.000 \%$ \\
\hline Indium & 2875 & Valero and Botero (2002) & 600 & 1725000 & $0.000 \%$ \\
\hline Iridium & 2100 & Ashby (2013) & 4 & 8400 & $0.000 \%$ \\
\hline Lanthanum & 219 & $\begin{array}{l}\text { Tharumarajah and Koltun } \\
\text { (2011) }\end{array}$ & 25000 & 5485000 & $0.001 \%$ \\
\hline Lead & 20 & Rankin (2011) & 5200000 & 101764000 & $0.019 \%$ \\
\hline Lead (ISP) & 33 & Rankin (2011) & 5200000 & 169052000 & $0.032 \%$ \\
\hline Lithium & 433 & Valero and Botero (2002) & 37000 & 16002500 & $0.003 \%$ \\
\hline Magnesium & 437.3 & Valero and Botero (2002) & 6350000 & 2776855000 & $0.532 \%$ \\
\hline Manganese & 56.9 & Valero and Botero (2002) & 17000000 & 967300000 & $0.185 \%$ \\
\hline
\end{tabular}




\begin{tabular}{|c|c|c|c|c|c|}
\hline Mercury & 409 & Valero and Botero (2002) & 1810 & 740290 & $0.000 \%$ \\
\hline Molybdenum & 148 & Valero and Botero (2002) & 250000 & 37000000 & $0.007 \%$ \\
\hline Neodymium & 392 & $\begin{array}{l}\text { Tharumarajah and Koltun } \\
\text { (2011) }\end{array}$ & 21080 & 8263360 & $0.002 \%$ \\
\hline Nickel (hydro) & 194 & Rankin (2011) & 2100000 & 406917000 & $0.078 \%$ \\
\hline Nickel (pyro) & 114 & Rankin (2011) & 2100000 & 238392000 & $0.046 \%$ \\
\hline Palladium & 5500 & Ashby (2013) & 200 & 1100000 & $0.000 \%$ \\
\hline Platinum & 270500 & Ashby (2013) & 179 & 48419500 & $0.009 \%$ \\
\hline Praseodymium & 220 & $\begin{array}{l}\text { Tharumarajah and Koltun } \\
\text { (2011) }\end{array}$ & 2800 & 616280 & $0.000 \%$ \\
\hline Rhenium & 171 & Valero and Botero (2002) & 5 & 855 & $0.000 \%$ \\
\hline Rhodium & 14200 & Ashby (2013) & 25 & 355000 & $0.000 \%$ \\
\hline Silver & 1582 & Valero and Botero (2002) & 24000 & 37968000 & $0.007 \%$ \\
\hline Steel & 23 & Rankin (2011) & 1500000000 & 34050000000 & $6.519 \%$ \\
\hline Tantalum & 1755 & Valero and Botero (2002) & 765 & 1342575 & $0.000 \%$ \\
\hline Tin & 207 & Valero and Botero (2002) & 230000 & 47518000 & $0.009 \%$ \\
\hline Titanium & 430 & Valero and Botero (2002) & 190000 & 81662000 & $0.016 \%$ \\
\hline Tungsten & 357 & Valero and Botero (2002) & 75700 & 27024900 & $0.005 \%$ \\
\hline Vanadium & 517 & $\begin{array}{l}\text { Valero and Botero (2002) } \\
\text { Tharumarajah and Koltun }\end{array}$ & 74000 & 38258000 & $0.007 \%$ \\
\hline $\begin{array}{l}\text { Yttrium } \\
\text { Zinc }\end{array}$ & 756 & (2011) & 10000 & 7559000 & $0.001 \%$ \\
\hline (electrolytic) & 48 & Rankin (2011) & 13000000 & 629720000 & $0.121 \%$ \\
\hline Zinc (ISP) & 36 & Rankin (2011) & 13000000 & 466050000 & $0.089 \%$ \\
\hline Zirconium & 1371.5 & Valero and Botero (2002) & 1440000 & 1974960000 & $0.378 \%$ \\
\hline \multicolumn{2}{|c|}{$\begin{array}{l}\text { Metal sector energy } \\
\text { consumption in } \mathbf{2 0 1 2} \text { (GJ) } \\
\text { Primary energy production in } \\
2012 \text { (GJ) }\end{array}$} & & & 52211442690 & $10.525 \%$ \\
\hline
\end{tabular}

Conversely, the energy sector consumes a large part of the different metals that are produced across the world. Bihouix and De Guillebon (2010) have evaluated that between 5 to $10 \%$ of global steel production is absorbed by the energy sector. It is unfortunately really complicated to give more details about the level of consumption of each metal in the energy sector. However, various studies have demonstrated that the intensity of rare metals per unit of delivered energy of renewable technologies (such as wind turbines and PV) is higher than for the infrastructure used in the production of fossil-based electricity (UKERC, 2013ab; SEI, 2012; Pihl et al, 2012; Yang, 2009; Kleijn et Van der Voet, 2010; Elshkaki et Graedel, 2013; Moss et al, 2013), and that this is also true for base metals and even common minerals (Pihl et al, 2012; Vidal et al, 2013; Lund, 2007; Kleijn et al, 2011; Elshkaki et Graedel, 2013; Ashby, 2013). This means that renewable technologies require more rare and common metals and minerals per installed MW compared to fossil-based electricity production. For the interest of the reader and a later use in this article, we have synthetized the metal requirements of the different renewable technologies taken into consideration in this article in Appendix A. 
Consequently, an energy transition toward renewables would require increasing metal consumption (at equivalent installed capacity).

\subsection{Evolution of the energy cost associated with metal production}

Extracting and refining metals require consuming energy, so it is easy to define an energy cost of production expressed in GJ per ton of extracted metal. We have already given some numerical data on energy cost in Table 1, but it would be interesting to assess the evolution of the energy cost associated with metal extraction and production. Such temporal analysis is important to see how the energy cost associated with metal extraction and production is related to cumulative production.

A first approach consists in analyzing the Energy Balance Flows established every year by the IEA. We have extracted some results from such analyses and presented them in Figure 1, where the evolution of the final energy consumption of various sectors and the global economy can be compared.

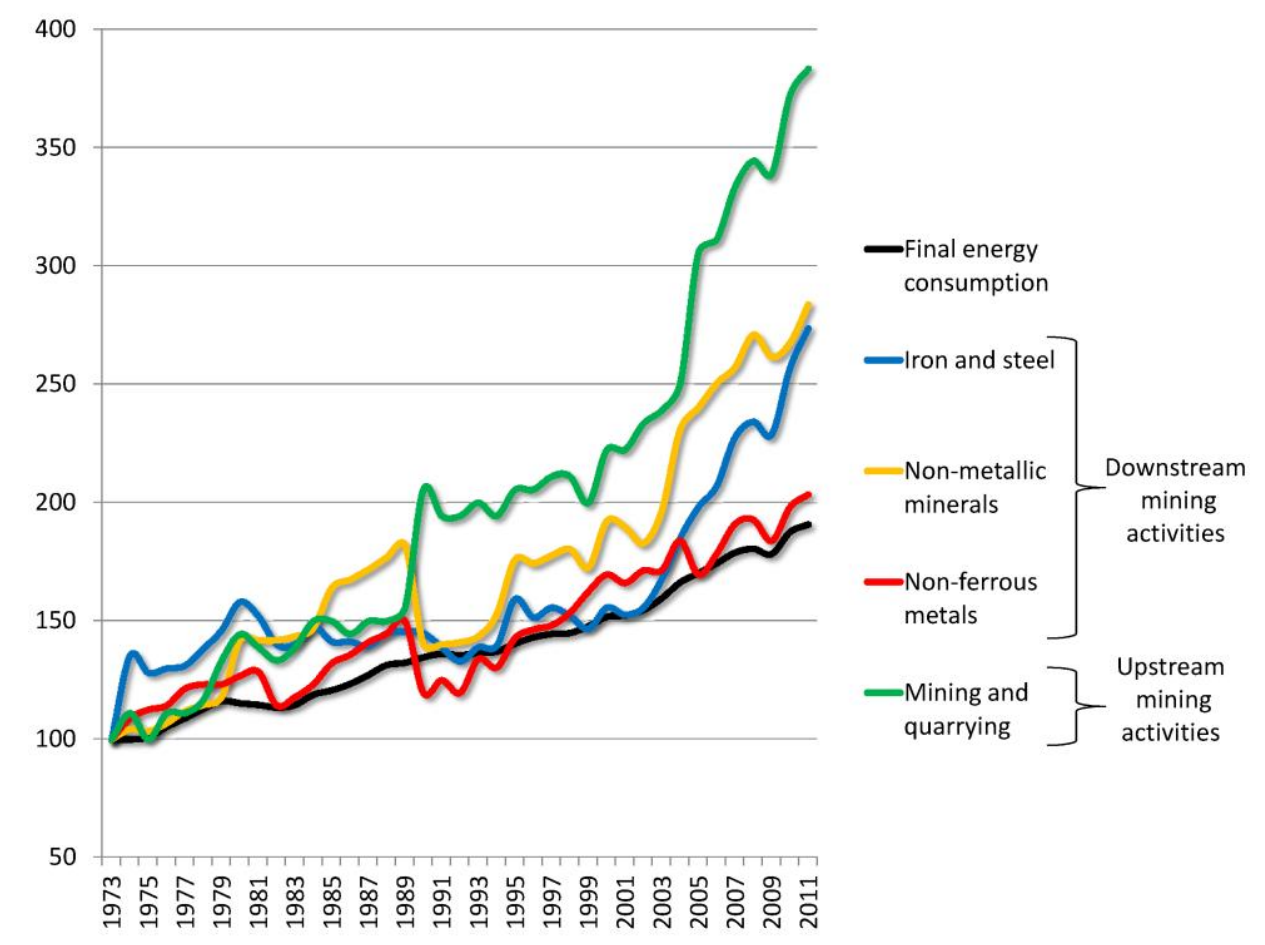

Figure 1 Evolution of the final energy consumption of different sectors and the global economy (based 100 in 1973). Source: IEA, 2014.

In Figure 1, mining activities (green line) represent all global upstream activities related to mineral extraction and concentration for both metal and non-metal matter (although fossil fuels like coal are not included). All other final energy consumptions refer to global downstream activities, for either metal refining (blue and red lines), or non-metallic minerals (such as sand, clay, etc.) manufacturing (red line). We can see from this figure, that between 1973 and 2011, the final energy consumption of the upstream mining sector (green line) has increased twice as much as the global economy did (black line). 
Sectors of metal and non-metal refining (blue, red and yellow lines) have also increased their energy consumption in a larger magnitude than the global energy consumption, but in a lesser order than the upstream mining sector. A reason for such increase is simply the increasing amount of minerals that is extracted from the environment due to increasing demand (i.e. a general volume effect). However, a second, and to our mind more crucial reason for this increasing energy consumption of metal sectors (and especially upstream mining activities) is the increasing unitary energy cost of metal extraction due to the qualitative depletion of mineral deposits. This hypothesis is comforted by Figure 1, taking into account that upstream activities, which support metal concentration, are sensitive to ore grade; whereas downstream activities, which represent refining of metals, are insensitive to ore grade.

The economic rationality imply to first consume metals from deposits where they are easily accessible and the less costly to extract (so most often where they are highly concentrated and close to the surface) and then to pursue with deposits less concentrated when the first are exhausted. For instance, according to Mudd (2010), between the mid-nineteenth century and 2006, the average grade of copper in Australia fell from nearly $23 \%$ to less than $2 \%$. Therefore, the more you deplete a metal stock, the lower the concentration of the metal, the higher the unitary energy cost of extraction. This has been reported, both at a local deposit level (Crowson, 2012), at national level (Mudd, 2010), and at worldwide level (Crowson, 2012; Schodde, 2010). More precisely, as the concentration of a given metal decreases, the energy cost associated with its extraction increases through an inverse mathematical relation of power type (see Figure 2). This relation has been precisely documented for copper, nickel and uranium (Page and Creasey, 1975; Mudd and Diesendorf, 2008; Memary et al., 2012; Northey et al., 2013; Norgate and Jahanshahi, 2010). In Figure 2, results of this relation from Norgate and Jahanshahi (2010) in the specific case of copper can be compared to a larger regression (that we will use later in this article) that we have operated on data for 34 different metals ${ }^{4}$. The relation that is expressed in Figure 2 comes from an econometric regression, which results are presented in Table 2.

Table 2 Main results for the regression based on 34 metals represented in figure 2.

\begin{tabular}{lcrrr} 
Dependent Variable: LOG(CONSUMPTION) & & & \\
Method: Least Squares & & & & \\
Included observations: 34 & & & & \\
\hline Variable & Coefficient & Std. Error & t-Statistic & Prob. \\
C & 5.632090 & 0.240914 & 23.37803 & 0.0000 \\
LOG(GRADE) & -0.600260 & 0.089179 & -6.730985 & 0.0000
\end{tabular}

\footnotetext{
${ }^{4}$ The list of the 34 metals is as follows:

Aluminum, Antimony, Arsenic, Beryllium, Bismuth, Cesium, Chrome, Cobalt, Copper , Gallium, Germanium, Gold, Hafnium, Indium, Iron, Lead, Lithium, Magnesium, Manganese, Mercury, Molybdenum, Nickel, Platinum, Rhenium, Silver, Tantalum, Tin, Titanium, Tungsten, Vanadium, Zinc, Zirconium, Praseodymium, Neodymium.
} 


\begin{tabular}{llll} 
R-squared & 0.586061 & & \\
Durbin-Watson & 2.167702 & & \\
White test & 2.778711 & Prob. Chi-Square(2) & 0.2492 \\
Jacque Berra & 2.767398 & Prob. & 0.2507 \\
\hline
\end{tabular}

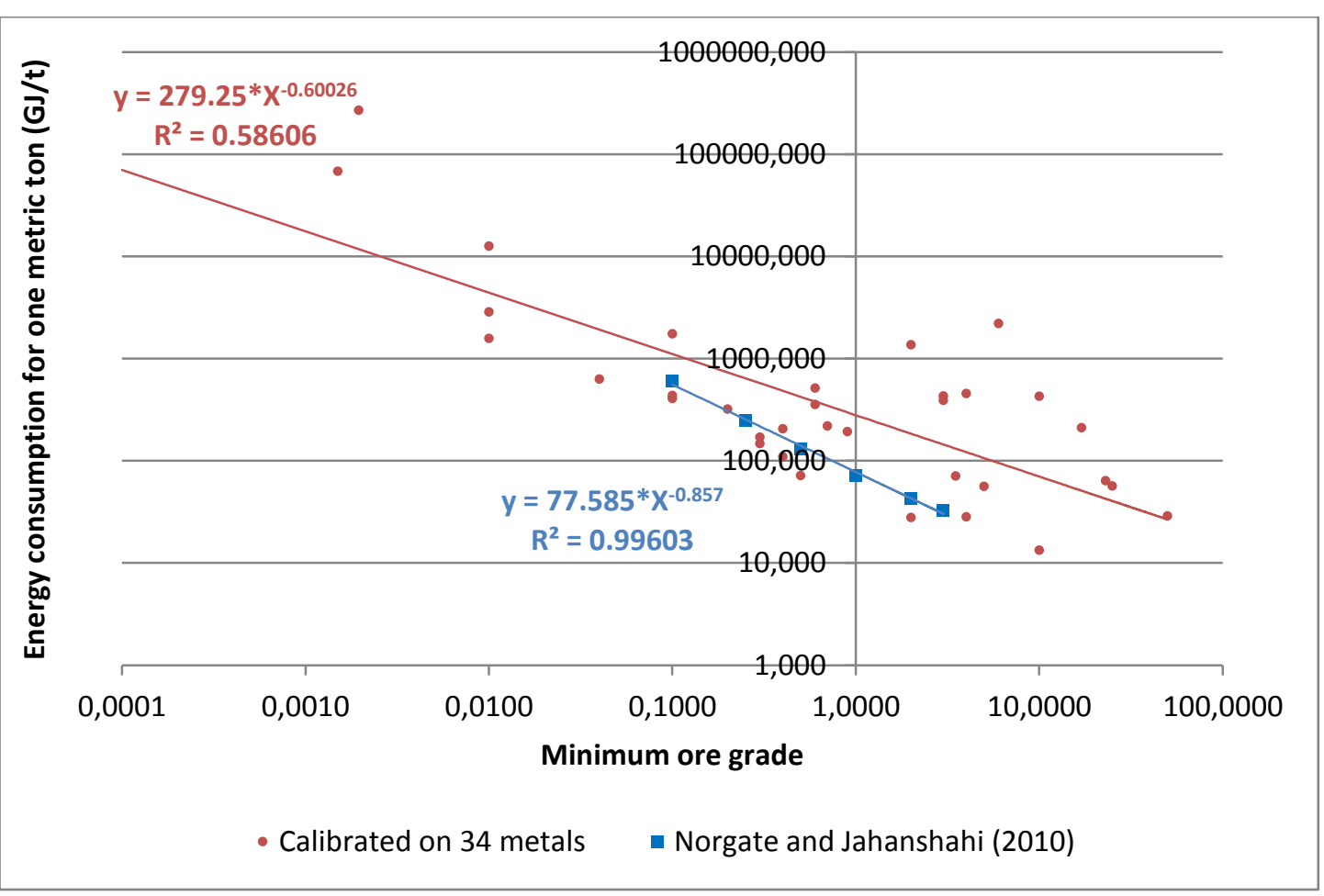

Figure 2 Relation between ore grade and energy cost of extraction. Blue line refers to copper only, based on data from Norgate and Jahanshahi (2010). We have produced the red line that exhibits the same relation using an econometric regression on 34 different metals.

The econometric regression that we have performed show that the relation between energy cost of extraction (Y) and ore grade (X) can be estimated by the equation $Y=279.25 * X^{-\alpha}$, with best estimate for $\alpha=-0.60026$ and a $95 \%$ confidence interval of $(-0.418609 ;-0.781910)$ for this same variable.

However, it must be stated that all metals will not follow the declining trend presented in figure 2 at the same speed. Indeed, the speed of the ore grade degradation is different for each metal. Data from the USGS presented in figure 3 show that the cumulative production of rare metals (such as gold, silver, copper, nickel, platinum, palladium, and rare earth elements) plus the reserves associated to these metals compared to their natural abundance in the earth's crust is higher than for common metals (such as iron, aluminum, silicon, magnesium, manganese, and titanium). On this same figure, the natural abundance of the different metals (represented by the three black lines) is obtained by multiplying the average grade of these metals in the continental crust by the mass of the continental crust in the top three kilometers, while the green and red regression lines (power fit) represent the relationship between the natural abundance of metals and their economic consumption (cumulative production plus reserves). Two points have to be mentioned here: first, the economic consumption of metals compared to their natural abundance is relatively imbalanced 
in favor of geochemically rare metals (comparison of the regression lines with the three black lines). Second, between 1996 and 2012, the ratio of economic consumption to natural abundance increased faster for geochemically rare metals than for common metals (comparison of the slope of the two regression lines). It means, as already highlighted by Skinner (1976), that we tend to accelerate the depletion speed of rare metals more rapidly than for common metals.

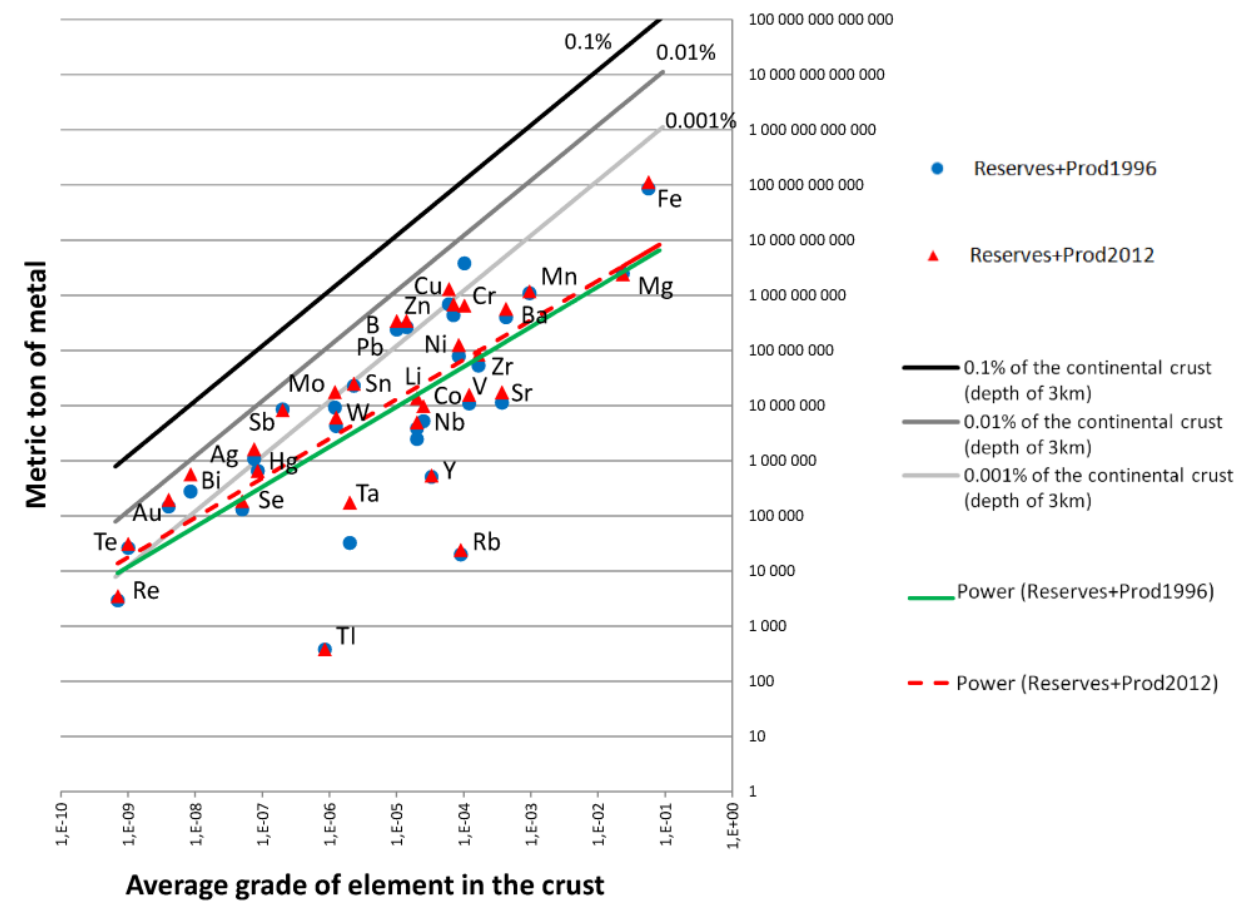

Figure 3 Unbalanced anthropogenic consumption of metals in favor of geochemically rare metals. Reading: the graph shows that we consume more rapidly rare metals than common metals. Indeed, the green and red regression lines represent the economic consumption of metals (cumulated consumption + Reserves) while the black and grey lines show the natural abundance of the different metals in the continental crust. The difference between the green and red line reveals the part of the natural abundance of metals which has been consumed for human needs between 1996 and 2012. Source: data of USGS, calculation by authors.

The question that then arises regards the impact of the energy cost of metal extraction on the energetic balance of renewable technologies. Energy technologies are useful only if they are able to deliver more energy to society than what is necessary to build and maintain their infrastructures and support their daily energy requirements.

\section{Methodology}

\subsection{Net energy and EROI concepts}

The concept of net energy was first enunciated by Howard T. Odum when he stressed in Energy, ecology and economics (1973) that it is not sufficient to look at the quantitative volumes of energy that are available, i.e. stock resources, because the most important variable is the quantity of energy that is really available to society once the energetic system has been supplied for its energy needs. Charles Hall (1972) formally introduced a derivative statistic of net energy, the Energy-Return-On- 
Investment, or EROI. As a derivative concept, EROI uses the same variables as net energy for its formulation, however resulting in a dimensionless ratio as can be seen in equation (1) and (2):

Net Energy = Gross Energy produced - Energy Invested to get that Energy

$$
E R O I=\frac{\text { Gross Energy Produced }}{\text { Energy Invested to get that Energy }}
$$

Net energy and EROI are logically related according to (3):

$$
\text { Net Energy }=\text { Gross Energy Produced } * \frac{E R O I-1}{E R O I}
$$

The EROI is a unitless ratio used to compare outputs to inputs and is therefore more convenient than net energy, which is a finite amount of energy (Murphy and Hall, 2011). An EROI ratio of " $20: 1$ " has to be read "twenty to one" and implies that a particular process or energy source yields 20 Joules on an investment of 1 Joule. The numerator and the denominator of the EROI ratio have to encompass the same boundary in order to clearly represent a net energy ratio of a precise entity. In fact, most controversies surrounding EROI analyses between fuels such as gasoline and corn-based ethanol for example are biased because they do not involve the same boundaries (Murphy et al., 2011). These same authors and others (e.g. Cleveland, 2005) also emphasised the need for energy quality correction in EROI analysis. Indeed, it is easily understandable that $1 \mathrm{MJ}$ of coal has not the same quality as $1 \mathrm{MJ}$ of oil because of differences in energy density, capacity to do useful work (i.e. exergy ${ }^{5}$ content), flexibility of storage and transport, cleanliness and so on. Following this idea, when the denominator of an EROI ratio is calculated, direct and indirect energy inputs have to be quality corrected and not simply expressed in heat equivalent units. Moreover, as indirect energy costs are most of the time not recorded by companies, energy inputs have often to be deduced by combining economic inputs and energy intensity factors. It is not the purpose of this article to deeply present the methodology that is used to calculate an EROI. This kind of information can be found in the appropriate literature: Hall et al., 1986; Berndt, 1978, 1990; Herendeen and Cleveland, 2004; Cleveland, 2005; Mulder and Hagens, 2008; Coughlin, 2011; Murphy et al., 2011; Brandt and Dale, 2011; Brandt et al., 2013a.

\footnotetext{
${ }^{5}$ The exergy of a system, also named available energy, is the maximum useful work that is potentially extractable during a process that brings the system into equilibrium with its surroundings. Whereas energy is conserved, exergy is destroyed during irreversible production/transformation processes.
} 


\subsection{EROI values for different energy resources}

A large number of studies have been conducted to estimate the EROI of different energy resources. We are not going to present all of them in details, though it would be really important to see differences in methodology and especially the boundaries involved in these different studies. Instead, we have reported in Appendix B a table that summarised the most up to date results that can be encountered in the literature relative to EROI estimations. Michael Dale performed a recent and large metaanalysis on EROI for the need of his PhD thesis (Dale, 2010). Lambert, Hall, Balogh and others used this basis and complete it in recent articles (Hall et al., 2014; Lambert et al., 2012). We have enhanced this work with only one reference: Weißbach et al., $2013 .{ }^{6}$

Looking at some sporadic values is in itself a source of information, but assessing the evolution of the EROI of as many energy resources as possible brings a lot more information regarding our energy resilience. Unfortunately, because of the lack of hindsight concerning renewables and unconventional fuels, EROI trends are especially present for conventional fossil fuels. Time-series analysis have been performed for: global oil (Gagnon et al., 2009), American oil and gas (Cleveland et al., 1984; and Hall et al., 1986; Guilford et al., 2011), Canadian oil and gas (Freise, 2011; Poisson and Hall, 2013), Norwegian oil and gas (Grandell et al., 2011), Mexican oil and gas (Ramirez et Hall, 2013), Chinese oil, gas and coal (Hu et al., 2011), Canadian dry gas (Freise, 2011), and American dry gas (Sell et al., 2011). All these studies present declining trends in recent decades with maximum EROI already passed.

This pattern necessarily raises some serious concerns, as our current industrialised complex societies have been built on the use of these high quality fossil energy resources, especially oil, that used to deliver huge amount of net energy and are now experiencing declining returns. More and more energy is invested in the energyextraction sub-system of our economy, making net energy delivered to society less available and fuels more expensive. For these reasons and others (pollution mostly) political and scientific attention is increasingly being paid to renewable source of energy, but as we have seen in this section (Appendix B), these forms of energy do not generate as much net energy as fossil energy used to do so. However, if we restrict our analysis to electricity production and without exploring the backup problem, renewable technologies such as wind turbines are promising with current EROI values equivalent to conventional means of electricity production. But as stated before, renewable technologies present higher matter-intensity than conventional fossil-based technologies. Therefore, the question of the impact of the energy cost

\footnotetext{
${ }^{6}$ As an anonymous reviewer accurately pointed out, it is always a problem to present EROI values without explicating the methodology and assumptions (in particular boundaries) used to calculate them. However, due to an evident lack of space, Appendix B only presents final values. Since references are provided for each EROI value, the reader is in the capacity of reviewing the respective studies in order to compare their methodologies.
} 
associated with metal extraction on the EROI of renewable technologies is of primarily importance.

\subsection{Assessing the impact of metal depletion on the EROI of renewable and nuclear technologies}

Two different calculations can be made in order to assess the impact of the energy cost associated with metal depletion on the EROI. A first approach consists in analysing the individual contribution of a given metal's energy cost of extraction on the EROI of a given technology. Another related method is explained thereafter in order to determine the impact of a general quality exhaustion of all metals incorporated in a given technology on its EROI.

Methodology for the calculation of the sensitivity of the EROI to one specific metal

First of all, for each technology $j$ it is possible to calculate the total energy produce, $\boldsymbol{E}_{\text {out }, \boldsymbol{j}}$, from one MW of installed capacity during its entire lifetime, $\boldsymbol{L}_{\boldsymbol{j}}$, by simply considering the load factor, $\boldsymbol{\sigma}_{\boldsymbol{j}}$, and that there is 8760 hours in one year:

$$
E_{\text {out }, j}=8760 * \sigma_{j} * L_{j}
$$

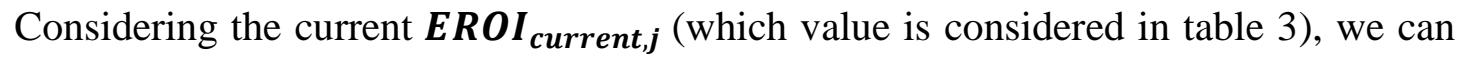
calculate the total energy invested, $\boldsymbol{E}_{\boldsymbol{i n}, \boldsymbol{j}}$, for one MW of a given technology:

$$
E_{\text {in }, j}=\frac{E_{\text {out }, j}}{E R O I_{\text {current }, j}}
$$

For each MW of technology $j, I$ different metals have been extracted and used in the construction of this MW of installed capacity. As metal extraction does not account for the totality of the energy invested in the energy system, we can define $\boldsymbol{\lambda}_{\text {current }, \boldsymbol{j}, \boldsymbol{i}}$, as the ratio of the energy invested for the extraction of metal $i, \boldsymbol{E}_{\text {metals,current, } i}$ (not depending on energy technology $j$, but solely on the metal type $i$ ) over the total energy invested, $\boldsymbol{E}_{\boldsymbol{i n}, \boldsymbol{j}}$ :

$$
\lambda_{\text {current }, j, i}=\frac{E_{\text {metals }, \text { current }, i}}{E_{\text {in }, j}}
$$

Similarly, $\boldsymbol{\lambda}_{\text {current }, \boldsymbol{j}}$, is the ratio of the energy invested for the extraction of all $I$ metals incorporated in technology $j$, over the total energy invested, $\boldsymbol{E}_{\boldsymbol{i n}, \boldsymbol{j}}$ :

$$
\lambda_{\text {current }, j}=\frac{\sum_{i} E_{\text {metals }, \text { current }, i}}{E_{\text {in }, j}}
$$


The current energy consumption due to the extraction of metal $i, \boldsymbol{E}_{\text {metals,current, } i}$, is obtained trough real data by combining Appendix A (metal intensity $i$ of technology $j$ in ton per MW, noted hereafter $\boldsymbol{\rho}_{\boldsymbol{i}, \boldsymbol{j}}$ ) and Table 1 (current unitary energy consumption, noted $\boldsymbol{\varepsilon}_{\text {current }, i}$ ) for each metal. But the current unitary energy consumption, $\boldsymbol{\varepsilon}_{\text {current }, \boldsymbol{i}}$, can also be estimated thanks to its relationship to the current metal ore grade, $\boldsymbol{\tau}_{\text {current }, i}$ as described in figure 2 and here in (8):

$$
\varepsilon_{\text {current }, i}=\mathrm{a} \times \tau_{\text {current }, i}{ }^{-\alpha}
$$

Where $\boldsymbol{a}$ and $\boldsymbol{\alpha}$ are two coefficients that are estimated through econometric analysis in order for the relationship described in (8) to match real data as presented in figure 2. Then, through this same relationship, we can compute the evolution of the unitary energy consumption, $\boldsymbol{\varepsilon}_{\text {evolved, } i}$, if we suppose that the concentration of the metal ore grade $i$ has moved from $\boldsymbol{\tau}_{\text {current }, i}$ to $\boldsymbol{\tau}_{\text {evolved }, i}$ :

$$
\varepsilon_{\text {evolved }, i}=\mathrm{a} \times \tau_{\text {evolved }, i}{ }^{-\alpha}
$$

Then, we can deduce the energy consumption due to the extraction of metal $i$ (from ore grade $\boldsymbol{\tau}_{\text {evolved,i }}$ ) per MW of energy system installed $j$ as a combination of the evolved unitary energy consumption previously calculated, $\boldsymbol{\varepsilon}_{\text {evolved }, i}$, and the metal $i$ intensity of the energy system $j, \boldsymbol{\rho}_{i, j}$ :

$$
E_{\text {metal,evolved }, i}=\rho_{i, j} \times \varepsilon_{\text {evolved }, i}
$$

With (10), we can now compute the energy share, $\boldsymbol{\lambda}_{\text {evolved }, j, i}$, of the metal $i$ in $E_{i n, j}$ :

$$
\lambda_{\text {evolved }, j, i}=\frac{E_{\text {metals }, \text { evolved }, i}}{E_{i n, j}}
$$

And we deduce $\boldsymbol{\lambda}_{\text {evolved },, i}$, as the share of the energy invested in technology $j$ through the extraction of metal $i$ with a degraded ore grade, and the extraction of all other metals except $i$ (noted $-i$ ) operated at constant ore grade (i.e. current):

$$
\lambda_{\text {evolved },, i}=\frac{\sum_{-i} E_{\text {metals }, \text { current },-i}+E_{\text {metal }, \text { evolved }, i}}{E_{i n, j}}
$$


Finally, we are able to calculate the $\boldsymbol{E R O I}_{\text {evolved }, j}$ of technology $j$, that is different

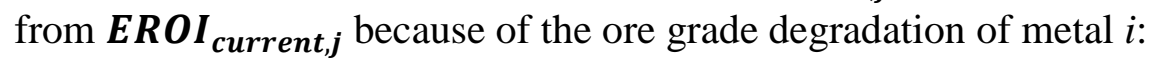

$$
\text { EROI }_{\text {evolved }, j, i}=\frac{\text { EROI }_{\text {current }, j}}{1-\lambda_{\text {current }, J}+\lambda_{\text {evolved }, J, i}}
$$

By choosing different potential $\boldsymbol{\tau}_{\text {evolved }, i}$ in a recursive process, one shall calculate the sensitivity of the EROI of a given technology to one particular metal.

Methodology for the calculation of the general sensitivity of the EROI to all metals

If we want to calculate the sensitivity of the EROI of a given technology to all metals incorporated in such technology ${ }^{7}$, we have to make an assumption about the speed of exhaustion of the different metals. Indeed, as previously stated the speed of this evolution will differ from one metal to another and depends mostly on the Clarke Value of the metal considered (studied by different authors: Craig et al, 2001; Valero et Botero, 2002; Rankin, 2011). This indicator is defined at a given time as the ratio of the minimal concentration for economical exploitation of a given metal (in the current period of exploitation) to its average concentration in crustal crust. Figure 4 exposes the relation we have established between the Clarke Value of copper and the multiplying factor that would affect the energy cost of copper extraction if the average concentration of this metal would go from its economic minimal concentration to its average crustal crust concentration (based on data from Norgate and Jahanshahi, 2010). We have extended this analysis to other metals (34 in total) and found a similar relation (Figure 4).

\footnotetext{
${ }^{7}$ In the following section, indices $j$ for the different technologies have been left out for convenience.
} 


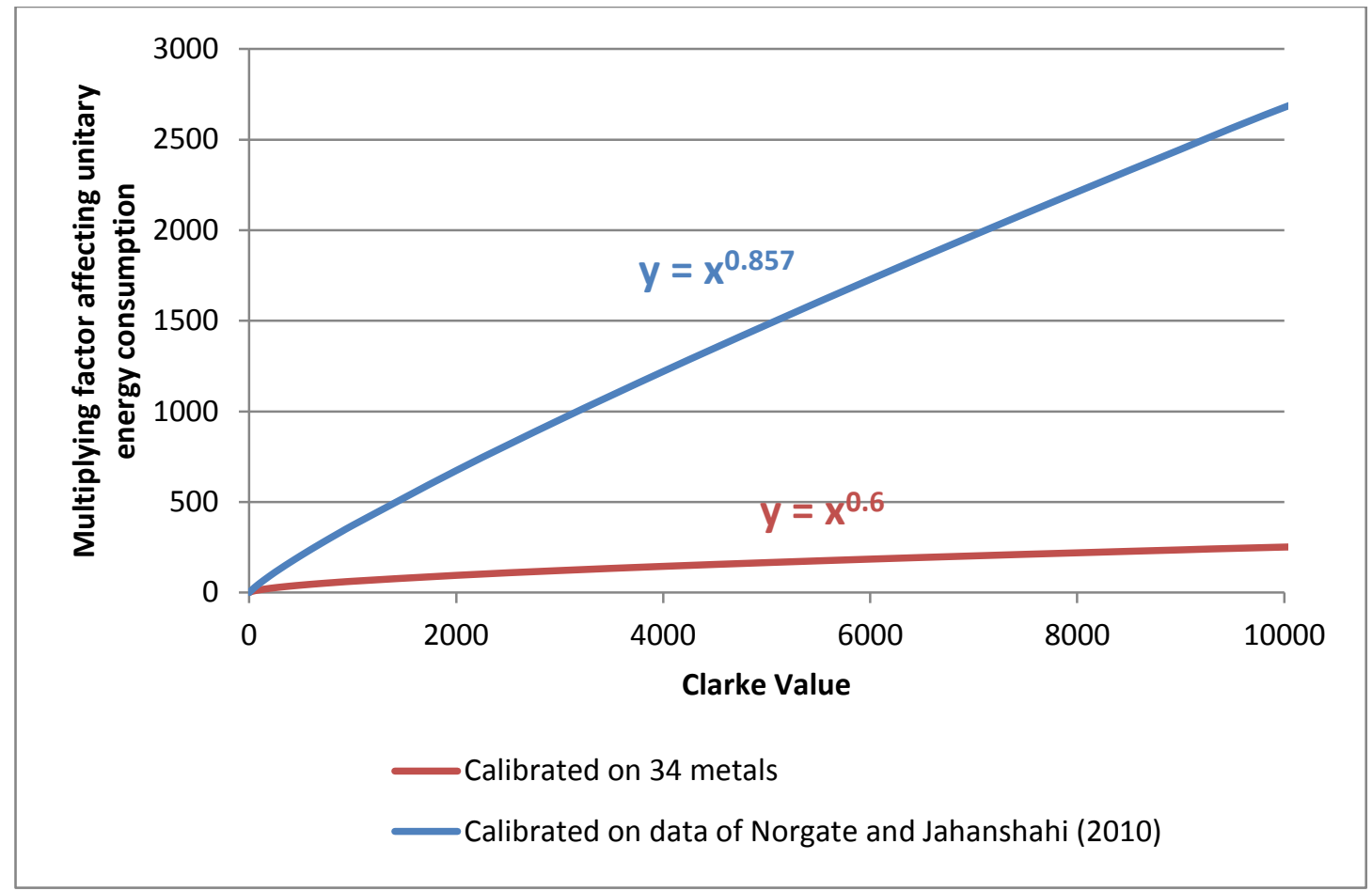

Figure 4 Relation between Clarke Value and multiplying factor affecting the energy cost of extraction if metal is extracted at average crustal crust. Blue curve represents relation for copper only, based on data of Norgate and Jahanshahi (2010), red curve represents the same relation calibrated on 34 different metals.

Figure 4 can be read as follows with the example of copper (blue line): typical copper deposit of minimal profitability have an ore grade of $0.5 \%$, whereas copper grade in common rocks is about $0.006 \%$. As a consequence, the Clarke Value of copper is approximately $83(0.5 / 0.006=83.33)$. Thus, exploiting copper from common rocks instead of concentrated deposit would imply multiplying the current energy cost of extraction by $45\left(83^{\wedge} 0.857=44.12\right)$. As a way of comparison in financial terms, Steen and Borg (2002) have shown that if metals were extracted from common rocks, financial cost associated with such exploitation would be multiplied by a factor 10 to 10,000 .

Thus, in order to build a methodology that enable us to test the sensitivity of the EROI to all metals, we will make the convenient assumption that all metals that are considered are depleted in the same proportion. As a consequence we will only consider geochemically rare metals because common metals have low Clarke Values, implying that for the latter a shift from concentrated deposits to common rocks would not induce a great change in their energy cost of extraction. Thus, in the following section we will consider geochemically rare metals only, and suppose that their ore grade is equally divided by a factor $\boldsymbol{\theta}$ through the extraction process. In this context, the relationship linking the ore grade, $\boldsymbol{\tau}$, to the initial unitary energy consumption, $\boldsymbol{\varepsilon}_{\text {initial }}$, is provided below:

$$
\varepsilon_{\text {initial }}=\frac{1}{\tau^{\alpha}}
$$


We wish to understand how the energy consumption is modified and equals $\boldsymbol{\varepsilon}_{\text {final }}$ when the ore grade is reduced by a factor $\boldsymbol{\theta}$ :

$$
\varepsilon_{\text {final }}=\frac{1}{\left(\frac{\tau}{\theta}\right)^{\alpha}}
$$

This can be rewritten in the equivalent form below:

$$
\varepsilon_{\text {final }}=\frac{1}{\tau^{\alpha}} \times \theta^{\alpha}
$$

As we want to know the multiplying factor, $\boldsymbol{\mu}$, affecting the unitary energy consumption when the ore grade is divided by the factor $\boldsymbol{\theta}$, we divide (16) by (14) and get (17):

$$
\mu=\frac{\varepsilon_{\text {final }}}{\varepsilon_{\text {initial }}}=\theta^{\alpha}
$$

Then, we use the previous equation (7) in order to obtain (18), where $\boldsymbol{\lambda}_{\text {global }}$ represent the share of the energy required for the production of all the different metals over the total energy invested in the energy system once all metals ore grades have been diminished by a factor $\boldsymbol{\theta}$ :

$$
\lambda_{\text {global }}=\frac{\sum_{k} \mu * E_{\text {metals,current }, k}}{E_{\text {in }}}
$$

Using (12), we are now able to calculate the evolution of the EROI, now called

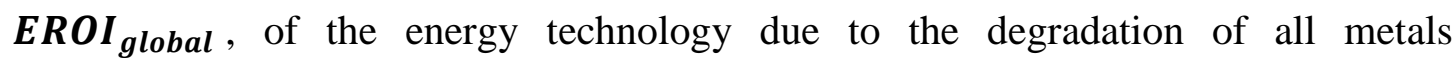
concentration by the same factor $\boldsymbol{\theta}$ :

$$
E R O I_{\text {global }}=\frac{E R O I_{\text {current }}}{1-\lambda_{\text {current }}+\lambda_{\text {global }}}
$$

By choosing different factor $\boldsymbol{\theta}$ in a recursive process, one shall calculate the sensitivity of the EROI of a given technology to all metals.

Data requirement for numerical applications

If one wants to perform numerical applications, both methodologies previously presented require data concerning: energy cost of metal extraction, metal requirement per electricity producing technologies, EROI, load factor and capital lifetime. Examples of such assumptions and are proposed in Table 1 (energy cost of metal 
extraction), Table 3 (metal requirement per electricity producing technologies) and Appendix A (EROI, load factor and capital lifetime).

Table 3 Hypotheses used for the calculation of a potential future EROI under metal scarcity.

\begin{tabular}{lllll}
\hline Technology & $\begin{array}{l}\text { Load } \\
\text { factor, } \boldsymbol{\sigma} \\
(\boldsymbol{\%})\end{array}$ & $\begin{array}{l}\text { Lifetime, } \\
\boldsymbol{L} \text { (years) }\end{array}$ & $\begin{array}{l}\text { Considered } \\
\text { current } \\
\text { EROI } \\
(\mathbf{X}: \mathbf{1})\end{array}$ & Reference for EROI \\
\hline Parabolic through & 33 & 30 & 20 & Weißbach et al., 2013 \\
Solar tower plant & 33 & 30 & 20 & Kreith and Krumdieck, 2013 \\
PV single Si & 10 & 25 & 6 & Raugei et al. 2012 \\
PV multi Si & 10 & 25 & 6 & Raugei et al. 2012 \\
PV a Si & 10 & 25 & 4 & $\begin{array}{l}\text { Raugei et al. 2012 ; Weißbach et al., } \\
\text { 2013 }\end{array}$ \\
PV CIGS & 10 & 25 & 6 & $\begin{array}{l}\text { Raugei et al. 2012 ; Weißbach et al., } \\
\text { 2013 }\end{array}$ \\
PV CdTe & 10 & 25 & 12 & Raugei et al., 2012 \\
Onshore Wind & 25 & 20 & 18 & Kubiszewski et al., 2010 \\
Offshore Wind & 35 & 20 & 18 & Kubiszewski et al., 2010 \\
Hydropower & 60 & 100 & 50 & Weißbach et al., 2013 \\
Nuclear & 80 & 40 & 10 & Hall and Day, 2009 \\
\hline
\end{tabular}




\section{Results of numerical applications}

4.1 Impact of specific metal scarcity on the EROI of different electricity producing technologies

Our methodology allows us to calculate the impact of the degradation of a specific metal ore grade on the EROI of different electricity producing technologies. Such calculation is in principle feasible for any metal that is used in a given technology but for the sake of clarity we choose to only show the results related to three metals: copper (figure 5), nickel (figure 6) and chromium (figure 7).

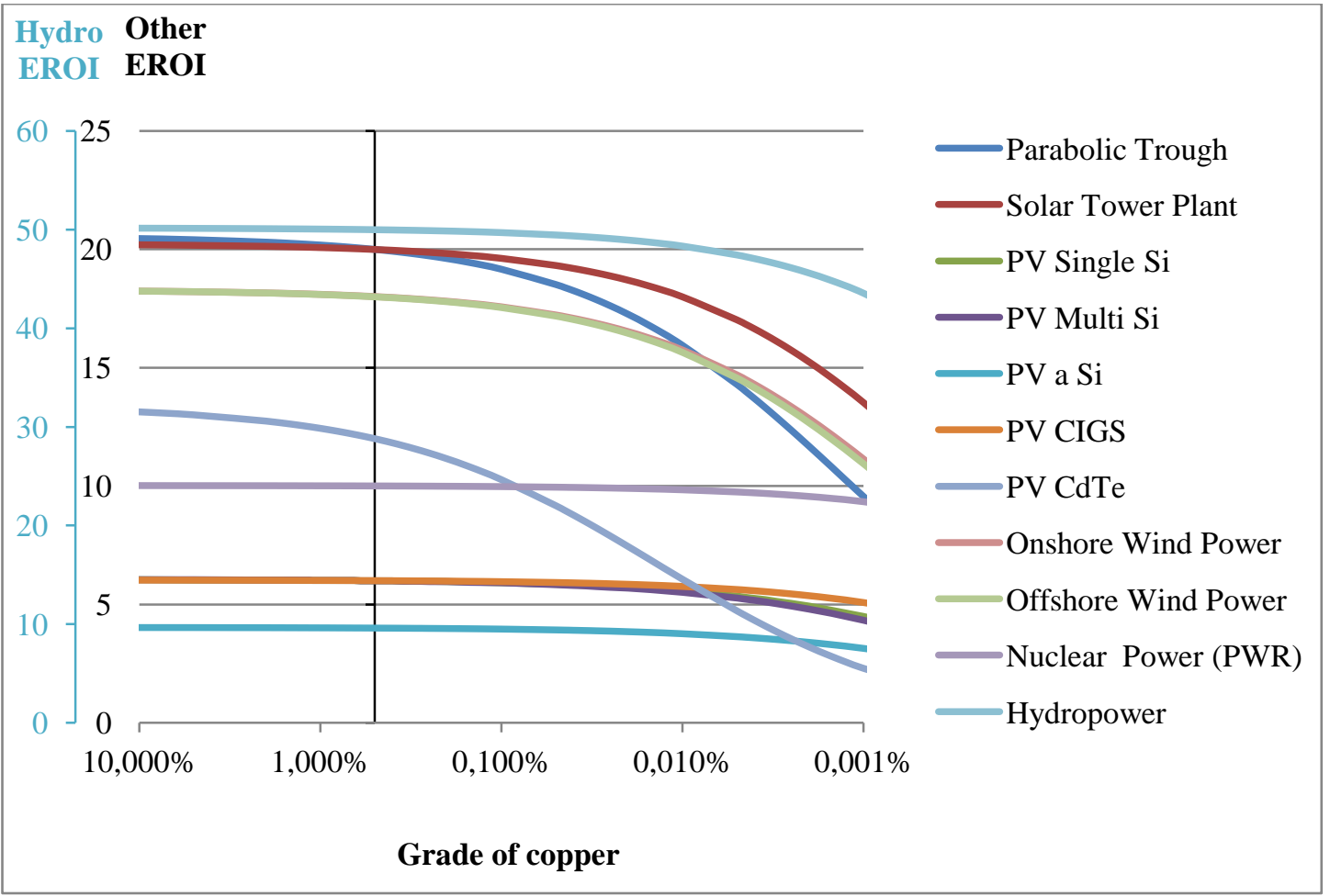

Figure 5 Sensitivity of the EROI of different energy technologies to the grade of copper (relationship: energy consumption $=1.397 *$ grade $\left.^{\wedge}-\mathbf{0 . 6 0 0 2 6}\right)$. The vertical bar represent current grade. 


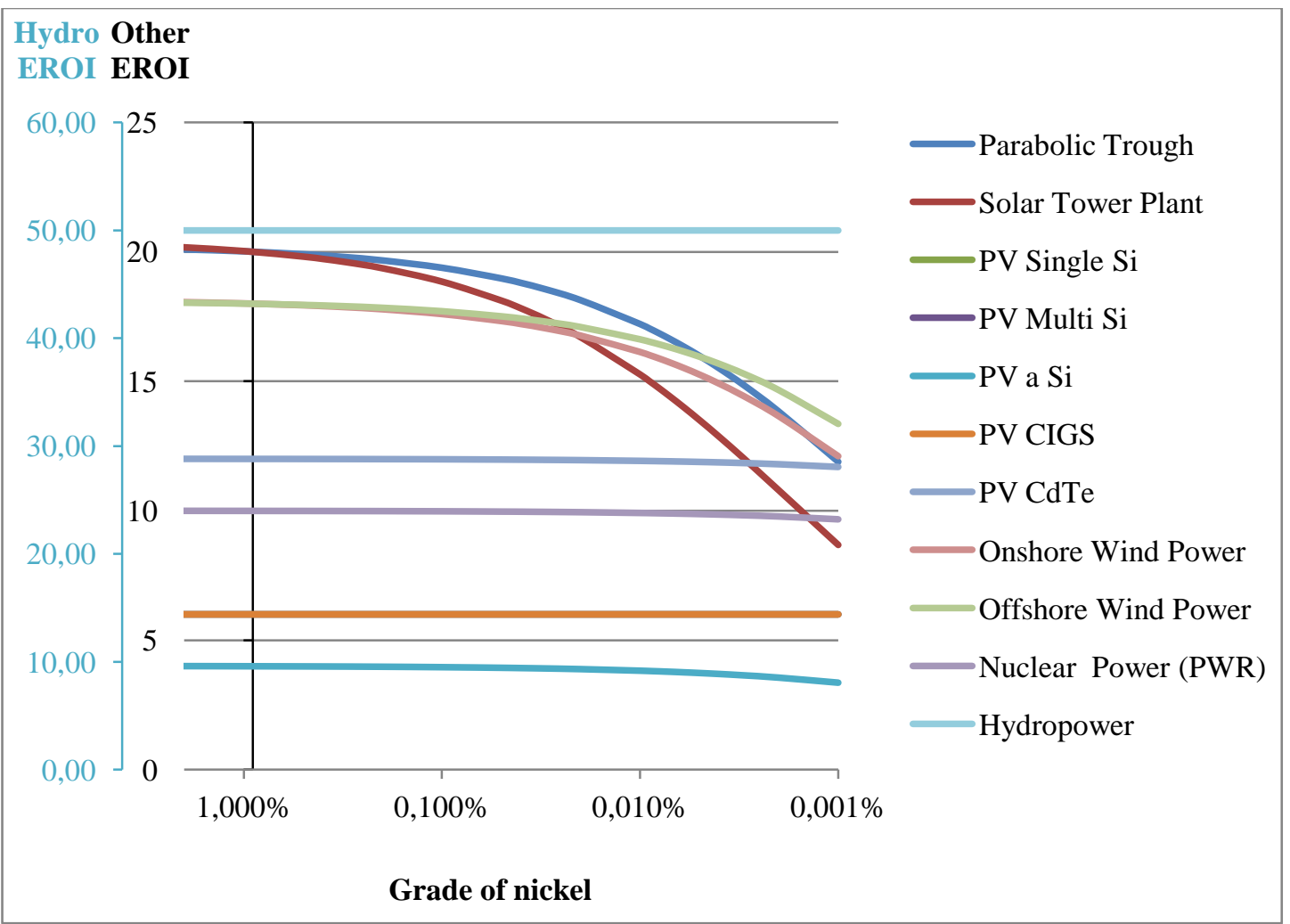

Figure 6 Sensitivity of the EROI of different energy technologies to the grade of nickel (relationship: energy consumption=11.463* grade $^{\wedge}-\mathbf{0 . 6 0 0 2 6}$ ). The vertical bar represent current grade.

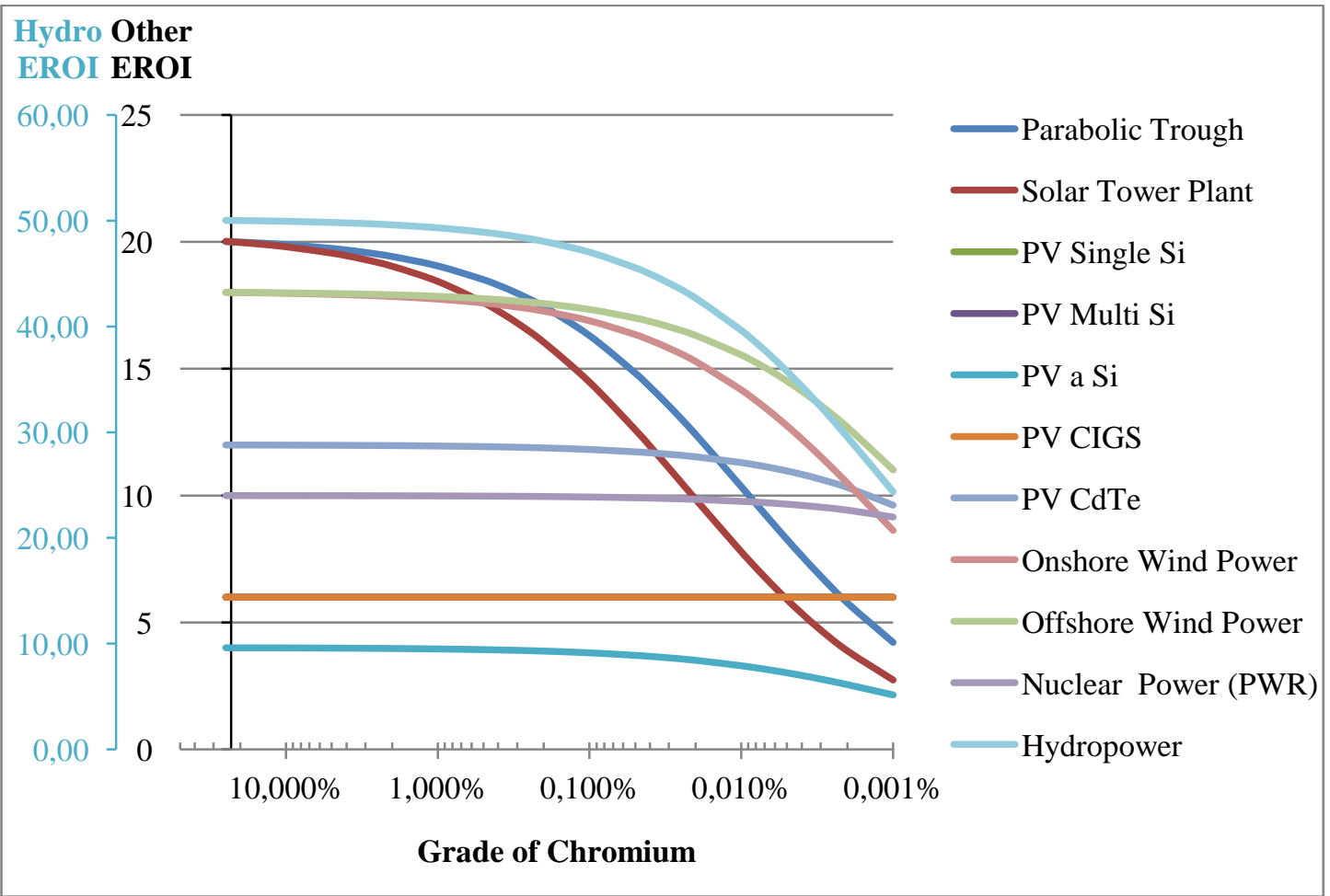

Figure 7 Sensitivity of the EROI of different technologies to the grade of chromium (relationship: energy consumption $=26.529 *$ grade $^{\wedge}-\mathbf{0 . 6 0 0 2 6}$ ). The vertical bar represent current grade.

A comparison of these different figures indicates that technologies are not equally sensitive to the three different metals (copper, nickel and chromium) we have chosen as examples. For instance, hydropower is more sensitive to chromium than copper 
because at the same extremely low concentration of $0.001 \%$, the EROI of hydropower is lower in the case of chromium ore grade degradation than in the similar case for copper. But one could say that because chromium is currently exploited in deposit with high concentration (23\%) compare to copper (0.5\%), the EROI of the different technologies will probably be impacted first by copper than chromium grade degradation. So we can see that trying to say that the EROI of a technology is more sensitive to a given metal compared to another depends not only on the level of diminution of its EROI, but also on the time at which this impact will start. This time horizon problem is out of the scope of our approach and would require building complex scenarios relying on different assumptions (GDP and population growths, intensity in the use of the different metals in the energy system and in other societal uses, etc). By way of illustration, Crowson (2012) has provided some data about the evolution of the grade of copper. According to this author, in 1800, the economical copper mines of the United of Kingdom were characterized by an average copper grade of nearly $9.27 \%$ and as previously stated an average value of $0.5 \%$ is now characteristic of copper mines. However, our calculations enable one to measure the sensitivity of the EROI of a given technology to any metal used in such technology.

To our knowledge, only one peer reviewed study from Harmsen et al. (2013) has investigated the relation between energy cost of metal extraction and EROI. In their analysis, Harmsen et al. have investigated how the evolution of copper consumption and its associated energy cost of extraction could affect the EROI of wind turbines on a 2050 horizon, assuming different $100 \%$ renewable energy scenarios. Their results showed that the EROI of wind turbines would be marginally impacted (3\% of the original value) by copper consumption on this time period is only wind turbine system is studied. Taking into account grid and backup need would more importantly impact the EROI of the energy system (15\% decrease compare to initial value).

\subsection{Impact of general metal scarcity on the EROI of different electricity producing technologies}

We have developed an alternative to our first methodology in order to calculate the sensitivity of the EROI of the same technologies to all metals, considering a common degradation of their deposit's concentration. The result of this calculation is presented in figure 8 . 


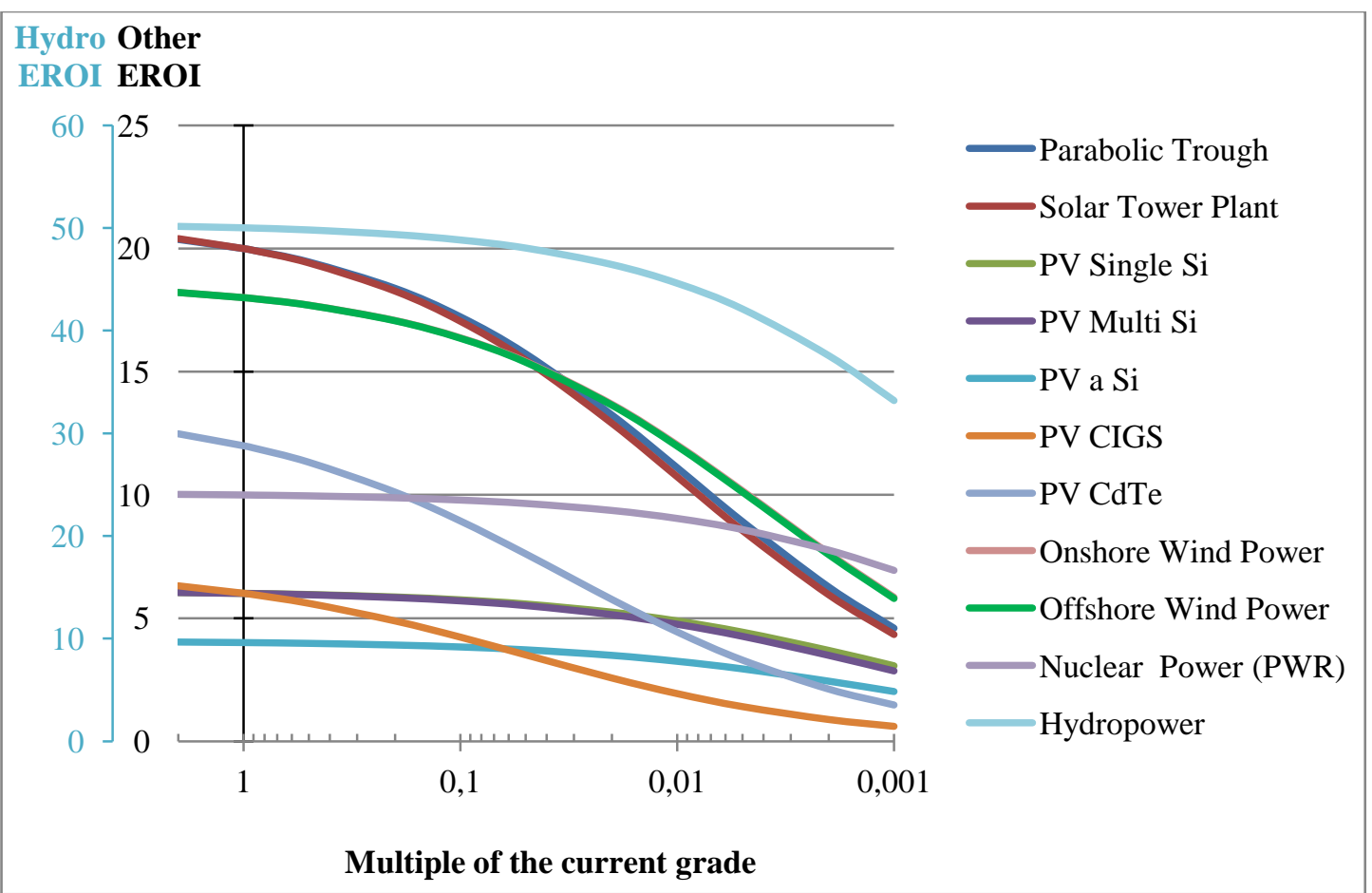

Figure 8 Evolution of the EROI of different energy technologies to a similar degradation of the grade of all geochemically rare metals. Reading: a multiple of the current grade of 0.1 means that the current grades of all geochemically rare metals are divided by a factor of 10. (Relationship: $\mu=\theta^{\alpha}$ where $\alpha=0.60026$ ).

In this case, all technologies are affected but not equally, which is rather logical. Some differences are worth pointing. In figures 5, 6 and 7, the evolution of the EROI of PV Multi Si and PV CIGS is pretty much the same and differences of impacts are hardly discernible. On the other hand, the evolution of the EROI of onshore and offshore wind power show discrepancies in figure 7 (sensitivity to chromium), whereas they exhibit the same behavior in figure 8 when all metals are accounted for, highlighting the existence of compensatory effects. This shows that taking into account all metals is important for a deep understanding of the impact of metal scarcity on the EROI of energy systems.

Our results also show that if rare metals would be extracted from deposit with ore grade approaching very low concentration (as we move on the far right of the different figures), the energy requirement would be so important that it would considerably decrease the EROI of all electricity producing technologies. Under this scenario, only few renewables (hydro and wind power) and nuclear would still present EROI well above the breakeven point. In such situation, wind turbines would still deliver net energy to society but as shown by King and Hall (2011) and Heun and De Wit (2012), this would surely imply that electricity produced in such condition would be really expensive. Indeed, these authors showed that EROI presents a non-linear relationship with market price of energy. Therefore, a decrease of the EROI from 10 to 4 is not equivalent to a fall of the EROI from 100 to 40 . According to the relationship provided by Heun and De Wit (2012), an EROI of 4 in the case of oil corresponds to an energy price of USD(2010) 280 per barrel of oil. 


\subsection{Sensitivity of our methodology}

As exposed before, in order to assess the sensitivity of the EROI of energy technologies to metal grade depletion, we have used the econometric relation presented in figure 2. As a consequence, our results are particularly sensitive to the value that is chosen for parameter $\alpha$. So far, results have been presented using the best estimate for this parameter. In particular, lower ore grades are underestimated with this mean $\alpha$, whereas using the upper estimate of the $95 \%$ confidence interval (that is 0.781910 instead of 0.60026 ) would put more weight on lower grade calculations. Figure 9 presents the same results as in Figure 8 regarding the sensitivity of the EROI to ore grade degradation of all metals but with an $\alpha$ of 0.781910 .

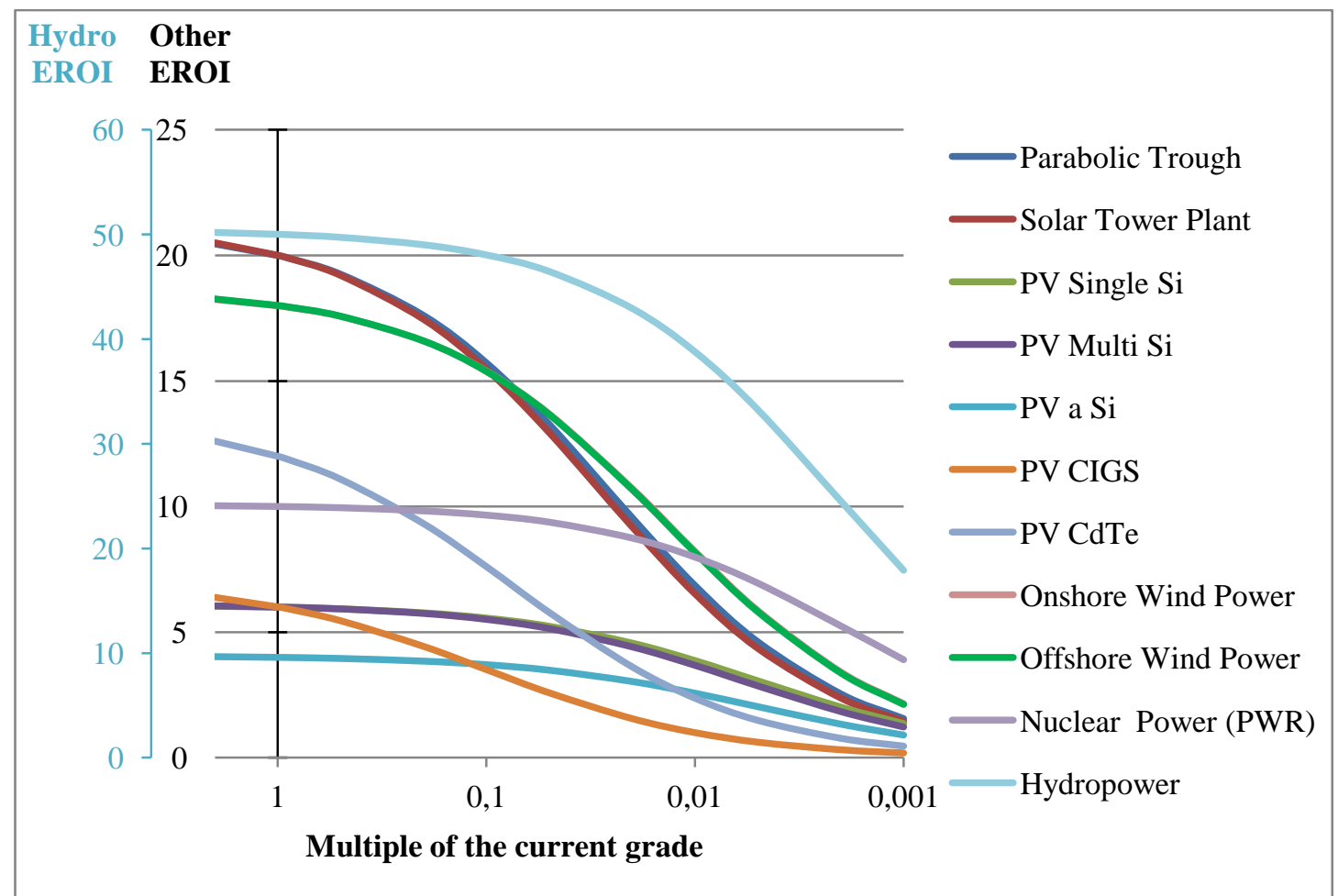

Figure 9 Evolution of the EROI of different energy technologies to a similar degradation of the grade of all geochemically rare metals. Reading: a multiple of the current grade of 0.1 means that the current grades of all geochemically rare metals are divided by a factor of 10 . (Relationship: $\mu=\theta^{\alpha}$ where $\alpha=0.781910$ ).

We can observe that under such conditions, the EROI of all technologies are logically more sensitive to important ore grade degradation. In figure 9, the decrease of all EROI is more important and occurs at less important ore grade degradation.

\section{Discussion}

Our analysis aimed at describing the close relationship that exists between energy and metal sectors. We have focused our analysis on the impact that the energy requirement associated with metal extraction could have on the EROI of different electricity producing technologies. First, the methodology we have developed allowed us to measure the sensitivity of the EROI of a given technology to the degradation of a particular metal ore grade (all other things remaining equal). Second, we have 
adapted this methodology to calculate the effect of a similar ore grade degradation of all the different metals used in a given energy system. These calculations definitely brought some light on the close relationship that exists between energy and metal sectors. The authors would like to emphasize that thanks to the methodology developed in this article, other analysts are now able to reproduce the calculations that have been made. This could be interesting especially if data relative to other/new technologies are found. As a matter of fact, it is obvious that the results of such computation are highly dependent on the quality of the data that is collected. Currently, data regarding energy cost of metal extraction and metal intensity in electricity producing technologies is rather scarce and subject to industrial secrecy. We think that there is a clear need to improve data quality in the future and that policy action should be taken in this direction (for example through research funding in data collection, or the establishment of industry standard and reporting).

It appears as highlighted in Appendix B that energy resources on which we have become accustomed and dependent, do not generate has much net energy as they used to do. Indeed, all fossil fuels present a declining EROI trend and unconventional fossil fuels present relatively low EROI. Renewable technologies with which we would like to replace these stock-based energy resources present EROI values that are lower than past fossil fuels EROI values. There is still room for technological progress to increase the EROI of these renewable technologies, but it will ultimately encounter a limit; and as already stated, renewable technologies are more capital-intensive than conventional means of energy production. This seems true for both common and rare metals. As depletion occurs for metals, the energy cost associated with their extraction increases following a highly non-linear behavior. In the context of a transition toward renewables, all other things being equal, the increasing energy requirement of the metal sector due to ore grade degradation would further increase the demand for renewable technologies. Moreover, the intermittency of these technologies implies the need to expand and reinforce the transmission grid, thus generating an even greater demand for metals. As a consequence, in the perspective of a transition toward renewable technologies, a potential vicious circle could developed between energy and metal sectors as summarized in Figure 10. 


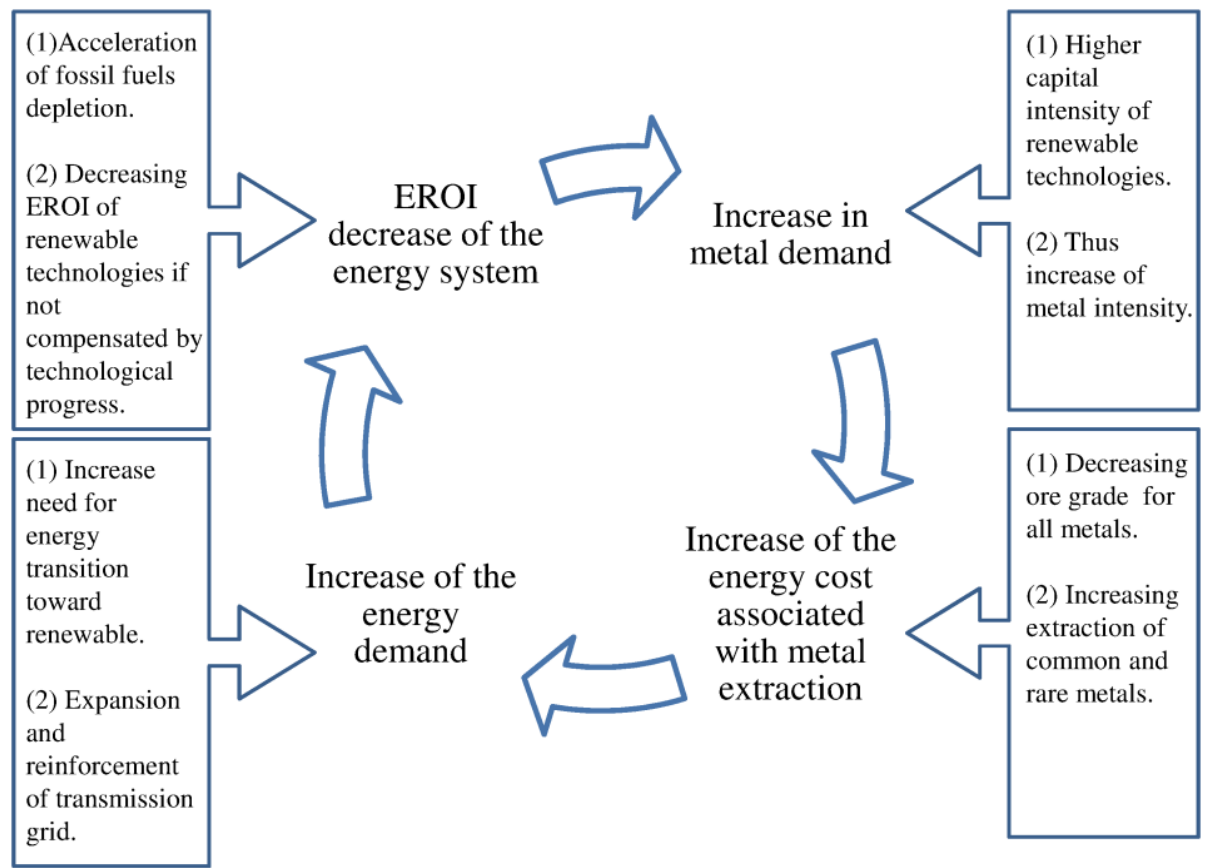

Figure 10 Potential vicious circle arising between energy and metal sectors in the case of a progressive energy transition toward $100 \%$ renewable technologies.

This self-enhancing relation between energy and metal sectors could be attenuated thanks to different levers:

- Recycling could slow down metal depletion but also decrease the energy requirement of the metal sector. Norgate and Haque (2010) gave the estimate of potentially 65 to $95 \%$ energy savings. However it must be stated that the effect of recycling is limited when the economy experiences continuous growth. Moreover, a $100 \%$ recycling efficiency is impossible due to physical dissipation as supported by the second law of thermodynamics (Ayres, 1999; Craig, 2001).

- Dematerialization of the economy that implies the consumption of less matter and energy per MW. However it must be stated that final energy always needs a minimum physical-based support to exist.

- Energy efficiency in order to lower energy requirement for metal extraction is also a solution. This is technological progress in a strict meaning of the term. According to different sources (Ruth, 1995; UNEP, 2013; Norgate and Jahanshahi, 2010, 2011) such sources of energy efficiency are quite large in metal sector, though ultimately limited by thermodynamics laws. In that regard, Ayres (2007) estimates that technical progress could reduce the energy required for the extraction and concentration of copper by no more than a factor two or three.

- Technical substitution of rare metals with common metals (Skinner, 1976) and others materials (Goeller and Weinberg, 1978). Nonetheless, as demonstrated 
by Messner (2002), incentives for substitution triggered by the price signal do not always lead to a modification of the production technology due to the presence of large switching costs. Moreover, the substitution process is affected by inertia and the research into substitutes (perfect or imperfect) needs time, money, and adequate economic incentives.

- Energy economies of scope through metal coproduction. As we will move on to less concentrated deposits, the opportunity of exploiting deposits with multiples metals coproduction will appear more advantageous than nowadays thanks to the possibility of scope economies. Indeed, metals produced as byproduct or coproduct (mainly minor metals) beneficiate from an energy credit as the energy cost associated with extraction and concentration is completely allocated to the primary ore and not to the byproduct. As a consequence, only the refining energy cost is allocated to minor metals. Nonetheless, even in the case of coproduction with only one primary metal that supports the energy cost of concentration, the exhaustion causes an important effect on the EROI (see our graphs on individual sensitivity).

- In the same way, economies of scale can be a good way to reduce the unitary energy consumption even if the general consequences of this kind of measure is largely unknown in term of ore grade degradation and total mining energy consumption.

On the other hand, other factors could accelerate and enhance the relation depicted in Figure 10:

- Geologist B.J. Skinner enunciated what he called a "mineralogical barrier". Under a certain threshold metal would not appear as "grains" in mineral but would substitute other atoms in the crystalline structure ${ }^{8}$. In this case, you would have to chemically break the totality of the mineral to recover the desired metal, which would prove to be really expensive from an energy perspective. Skinner (1976) even evoked a break in the relation between ore grade and energy cost of extraction (also discussed in Ayres, 2007).

- Future deposits that will be put into production will be deeper, and will probably contain more impurities. This will require more energy to convey ore to the surface and to operate a finer crushing (UNEP, 2013).

- Other environmental impacts have not been considered so far, such as waste management, water need, or green house gases emissions, etc. If the management of such negative externalities would be integrated, it would surely imply an additional energy cost.

- As already expressed by Harmsen et al. (2013), the energy cost associated with the construction and maintenance of other parts of the energy system, related to the transmission and distribution grid or to electricity storage, would induce a further reinforcement of the relation between energy and metal sectors previously depicted.

\footnotetext{
${ }^{8}$ For example, lead is a substitute for potassium at atomic scale, so is zinc for magnesium.
} 


\section{Summary and conclusions}

In this article we have analyzed the close relationship that exists between energy and metal sectors. Surely, one of the most important contributions of this paper is to underline that we cannot dissociate the issue of energy availability from the economic/energy availability of raw materials (especially metals). In other words, we have highlighted the importance of "quality depletion" compared to the more classical "quantity depletion" that is usually the focus of studies related to material issues. Our study also shows the interest of performing cross-sectorial analysis in order to highlight hidden issues in conventional assessments. First, we have supported the position of Rankin (2011) by estimating that $10 \%$ of the global primary energy production is consumed by the metal sector. Then, we showed that the energy consumption of the metal sector has increased faster than the rest of the economy since 1973. Supported by previous studies, we made the fair assumption that this apparent increasing energy requirement of the metal extraction sector is mainly due to decreasing ore grade. Declining quality of mineral is a natural process that occurs at different level (deposit, nation, world) and implies that more energy is needed to extract a given quantity of metal. Because renewable technologies have higher metal intensities compared to conventional means of electricity production, the question of the sustainability of a transition consisting in a shift toward renewables is legitimate. On the other hand, we have presented results from various studies regarding the EROI of different energy resources. These studies demonstrate that fossil fuels, on which our complex industrialized societies have based their constructions, experience declining EROI; whereas renewable technologies present relatively low EROI, except for hydro and wind power. Logically, we have decided to estimate how the energy requirement associated with metal extraction could impact the EROI of different electricity producing technologies.

A first analysis has consisted in the calculation of the sensitivity of the EROI of renewable and nuclear technologies assuming different ore grade degradation for a specific metal. We have exposed the kind of results that are possible to obtain through three metal examples (copper, nickel, chromium), although this kind of sensitivity calculation could be done for any metal used in a given technology. Each technology as a specific sensitivity to a particular metal that can be measured through the methodology we have developed. In a second step, we have adapted our methodology in order to calculate the combined effect of all metals on the sensitivity of the EROI of the same technologies. This exercise was useful to see that energy requirement associated with metal extraction could have a significant impact on the capacity of these "green" technologies to deliver net energy to society. Off course, the question of the speed of degradation of the average ore grade of a given metal remains unanswered. This evolution will be different for each kind of metal but will have ultimately a negative impact on the EROI of renewable technologies. 
However, we have emphasized the fact that heading to such unpleasant future could occur more rapidly than one shall assume due to the potential vicious circle that could arise between energy and metal sectors. We have discussed the possibilities of such vicious self-enhancing relation to appear in the perspective of a complete transition toward renewables. It is currently impossible to say if such unpleasant situation would effectively arise but we believe that our study has at least the merit of starting a quantitative exploration of this issue.

\section{Acknowledgments}

The authors would like to thank Dr.Pierre-André Jouvet, Dr. Catherine Baumont and Dr.Frédéric Lantz for their review and helpful comments on an earlier version of this article. Valuable data was provided by different people that the authors would like to thank: M-M. Quemere, F. Catier, M. Bordigoni, and A. Schell.

We would like to thank the three anonymous reviewers for their insightful comments that have added much to the quality of this paper. 
Appendix A: Metal intensity of different energy technologies

Source: Pihl et al. (2012), Ashby (2013) and EDF private data (not communicated)

\begin{tabular}{|c|c|c|c|c|c|c|c|c|c|c|c|}
\hline Ton per MW & $\begin{array}{c}\text { Parabolic } \\
\text { trough }\end{array}$ & $\begin{array}{c}\text { Solar } \\
\text { tower } \\
\text { plant }\end{array}$ & $\begin{array}{c}\text { PV } \\
\text { single } \\
\text { si }\end{array}$ & $\underset{\text { multi }}{\text { PV }}$ & $\underset{\mathrm{Si}}{\mathrm{PV} \mathbf{a}}$ & $\begin{array}{c}\text { PV } \\
\text { CIGS }\end{array}$ & $\begin{array}{c}\text { PV } \\
\text { CdTe }\end{array}$ & $\begin{array}{c}\text { Onshore } \\
\text { wind } \\
\text { power }\end{array}$ & $\begin{array}{c}\text { Offshore } \\
\text { wind } \\
\text { power }\end{array}$ & $\begin{array}{c}\text { Nuclear } \\
\text { Power } \\
\text { (PWR) }\end{array}$ & $\begin{array}{l}\text { Hydro } \\
\text { Power }\end{array}$ \\
\hline Cadmium & & & & & $\begin{array}{l}0.00 \\
661 \\
0.63\end{array}$ & 0.265 & $\begin{array}{l}0.24 \\
426 \\
0.06\end{array}$ & & & & \\
\hline Chromium & 2.2 & 3.7 & & 0.94 & $\begin{array}{c}4 \\
1.00\end{array}$ & & $\begin{array}{c}1 \\
5.18\end{array}$ & 0.3589 & 0.29356 & 0.35 & 1.5 \\
\hline Copper & 3.2 & 1.4 & 0.825 & 3 & 5 & 0.45 & 07 & 1.012 & 1.484 & 1.345 & 1.05 \\
\hline Galium & & & & & 0.01 & 0.124 & & & & & \\
\hline Indium & & & 0.0055 & 0.00 & 341 & 0.055 & 0.00 & & & & \\
\hline Lead & & & 3 & 632 & 0.01 & & $\begin{array}{c}78 \\
0.00\end{array}$ & & 0.07531 & 0.04 & 0.3 \\
\hline Molybdenum & 0.2 & 0.056 & & 0.00 & $\begin{array}{l}062 \\
0.33\end{array}$ & 0.109 & $\begin{array}{c}05 \\
0.01\end{array}$ & 0.0753 & 5 & & 0.25 \\
\hline Nickel & 0.94 & 1.8 & 0.0013 & 13 & 4 & & 559 & 0.3766 & $\begin{array}{l}0.37657 \\
0.03765\end{array}$ & 0.3 & \\
\hline Niobium & & & & & & & & 0.0377 & 7 & & \\
\hline Selenium & & 0.0170 & & 0.06 & & 0.11 & & & & & \\
\hline Silver & 0.01342 & 2 & 0.059 & 817 & 0.00 & & 0.24 & & & & \\
\hline Telurium & & & & & $\begin{array}{c}75 \\
0.14\end{array}$ & & 287 & & & & \\
\hline Tin & & & & & 321 & & & & & & \\
\hline Vanadium & 0.0019 & 0.0017 & 0.0156 & 0.01 & & & & 0.0904 & $\begin{array}{c}0.09037 \\
87\end{array}$ & & \\
\hline $\begin{array}{l}\text { Zinc } \\
\text { Praseodymiu } \\
\text { m }\end{array}$ & 0.65 & 1.4 & 2 & 785 & & 0.121 & & 0.0013 & 0.0308 & & 0.4 \\
\hline Neodymium & & & & & & & & 0.0062 & 0.15092 & & \\
\hline Terbium & & & & & & & & 0.0003 & 0.00616 & & \\
\hline Dysprosium & & & & & & & & 0.0009 & 0.02156 & & \\
\hline
\end{tabular}




\section{Appendix B}

\begin{tabular}{|c|c|c|c|c|}
\hline Resource & Year & Country & $\begin{array}{l}\text { EROI } \\
(\mathrm{X}: 1)^{*}\end{array}$ & Reference \\
\hline \multicolumn{5}{|l|}{$\begin{array}{l}\text { Conventional oil and gas } \\
\text { (combined production) }\end{array}$} \\
\hline Oil and Gas production & 1999 & Global & 35 & Gagnon et al., 2009 \\
\hline Oil and Gas production & 2006 & Global & 18 & Gagnon et al., 2009 \\
\hline Oil and Gas discoveries & 1970 & USA & 8 & $\begin{array}{l}\text { Cleveland et al. 1984; Hall } \\
\text { et al. } 1986\end{array}$ \\
\hline Oil and Gas production & 1970 & USA & 20 & $\begin{array}{l}\text { Cleveland et al. 1984; Hall } \\
\text { et al. } 1986\end{array}$ \\
\hline Oil and Gas production & 1955 & USA & 22.5 & Guilford et al. 2011 \\
\hline Oil and Gas production & 2000 & USA & 15 & Guilford et al. 2011 \\
\hline Oil and Gas production & 2007 & USA & 11 & Guilford et al. 2011 \\
\hline Oil and Gas importation & 2007 & USA & 12 & Guilford et al. 2011 \\
\hline Oil and Gas production & 1970 & Canada & 65 & Freise, 2011 \\
\hline Oil, Gas \& Tar sands production & 2010 & Canada & 11 & Poisson and Hall, 2013 \\
\hline Oil and Gas production & 2008 & Norway & 40 & Grandell, 2011 \\
\hline Oil and Gas production & 2009 & Mexico & 45 & Ramirez and Hall, 2013 \\
\hline Oil and Gas production & 2010 & China & 10 & Hu et al. 2011 \\
\hline \multicolumn{5}{|l|}{ Conventional oil alone } \\
\hline Oil production & 2008 & Norway & 21 & Grandell, 2011 \\
\hline \multicolumn{5}{|l|}{ Conventional dry gas } \\
\hline Natural gas production & 2005 & USA & 67 & Sell et al., 2011 \\
\hline Natural gas production & 1993 & Canada & 38 & Freise, 2011 \\
\hline Natural gas production & 2000 & Canada & 26 & Freise, 2011 \\
\hline Natural gas production & 2009 & Canada & 20 & Freise, 2011 \\
\hline Electricity production & $\mathrm{n} / \mathrm{a}$ & $\mathrm{n} / \mathrm{a}$ & 28 & Weißbach et al.2013 \\
\hline \multicolumn{5}{|l|}{ Unconventional fossil fuels } \\
\hline Deep off-shore oil & 2009 & $\begin{array}{l}\text { Gulf of } \\
\text { Mexico }\end{array}$ & 5.5 & $\begin{array}{l}\text { Moerschbaecher and Day, } \\
2011\end{array}$ \\
\hline Heavy oil & 2005 & California & 5 & Brandt, 2011 \\
\hline Tar sands & 2010 & Canada & 6 & Brandt et al. 2013b \\
\hline \multirow[t]{2}{*}{ Tar sands } & 1994 & & & \\
\hline & $\begin{array}{c}\text { to } \\
2008\end{array}$ & Canada & 4 & Poisson and Hall, 2013 \\
\hline Shale oil & $\mathrm{n} / \mathrm{a}$ & $\mathrm{n} / \mathrm{a}$ & $\mathrm{n} / \mathrm{a}$ & $\begin{array}{l}\text { Despite its interest, no } \\
\text { actual studies }\end{array}$ \\
\hline \multicolumn{5}{|l|}{ Oil shale } \\
\hline in situ technology & 2008 & & 1.8 & Brandt, 2008 \\
\hline retort shale technology & 2009 & & 2.2 & Brandt, 2009 \\
\hline \multicolumn{5}{|l|}{ Coal } \\
\hline Coal production & 1950 & USA & 80 & Cleveland et al. 1984 \\
\hline Coal production & 2000 & USA & 80 & Hall and Day, 2009 \\
\hline Coal production & 2007 & USA & 60 & $\begin{array}{l}\text { Balogh et al., in } \\
\text { preparation }\end{array}$ \\
\hline Coal production & 1995 & China & 35 & Hu et al. 2011 \\
\hline Coal production & 2010 & China & 27 & Hu et al. 2011 \\
\hline Electricity production & $\mathrm{n} / \mathrm{a}$ & $\mathrm{n} / \mathrm{a}$ & 30 & Weißbach et al.2013 \\
\hline \multicolumn{5}{|l|}{ Nuclear } \\
\hline Electricity production & $\mathrm{n} / \mathrm{a}$ & US & 5 to $15 ; 75$ & $\begin{array}{l}\text { Lenzen, 2008; Hall and } \\
\text { Day, 2009; Weißbach et } \\
\text { al.2013 }\end{array}$ \\
\hline
\end{tabular}




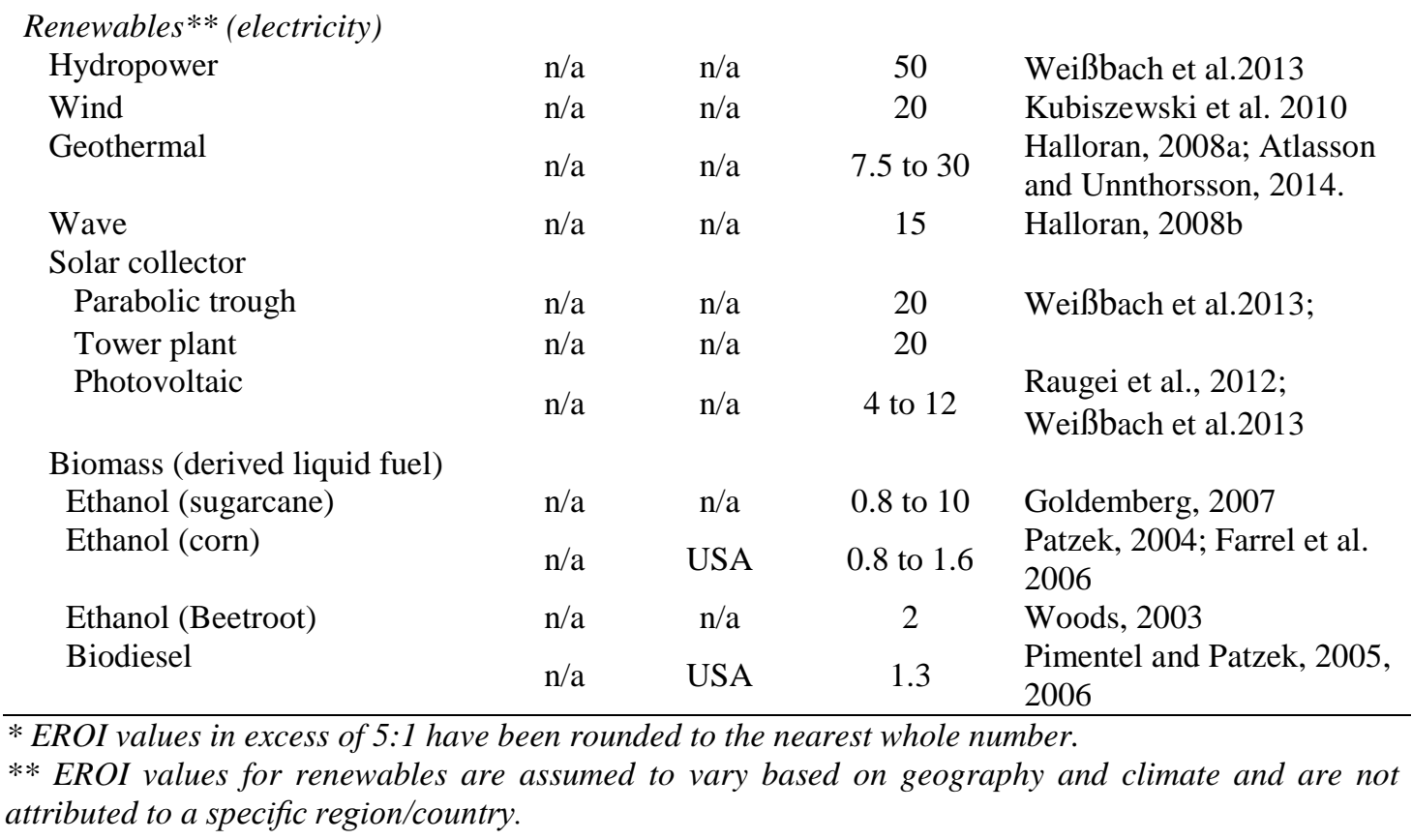




\section{References}

Ashby, M. F., 2013. Materials and the Environment: Eco-Informed Material Choice, Edition Butterworth-Heinemann, Elsevier, 2nd edition, 628p.

Ayres, R. U., 1999. The second law, the fourth law, recycling and limits to growth, Ecological Economics, 29 (3), 473-483.

Ayres, R. U., 2007. On the practical limits to substitution, Ecological Economics, 61, $115-126$.

Ayres, R., and V., Voudouris, 2014. The economic growth enigma: Capital, labour and useful energy? Energy Policy, 64, 16-28.

Bihouix, P., De Guillebon, B., 2010. Quels futurs pour les métaux ? Raréfaction des métaux : un nouveau défi pour la société, édition EDP sciences, 300p.

Brandt A.R, Dale, M., Barnhart, C.J., 2013a. Calculating systems-scale energy efficiency and net energy returns: A bottom-up matrix-based approach, Energy, 62, 235-247.

Brandt A.R., Dale, M., 2011. A General mathematical framework for calculating systems-scale efficiency of energy extraction and conversion: energy return on investment (EROI) and other energy return ratios, Energies, 4 (8), 1211-1245.

Brandt A.R., Englander, J., Bharadwaj, S., 2013b. The energy efficiency of oil sands extraction: Energy return ratios from 1970 to 2010, Energy, 53, 693-702.

Brandt, A.R., 2008. Converting oil shale to liquid fuels: Energy inputs and greenhouse gas emissions of the shell in situ conversion process, Environmental Science \& Technology, 42, 7489-7495.

Brandt, A.R., 2009. Converting oil shale to liquid fuels with the alberta taciuk processor: Energy inputs and greenhouse gas emissions, Energy \& Fuels, 23, 62536258.

Brandt, A.R., 2011. Oil Depletion and the Energy Efficiency of Oil Production: The Case of California, Sustainability, 3, 1833-1854.

Cleveland, C.J., 2005. Net energy from the extraction of oil and gas in the United States, Energy, 30, 769-782.

Cleveland, C.J., Costanza, R., Hall, C.A.S., Kaufmann, R., 1984. Energy and the U.S. economy: a biophysical perspective, Science, 225, 890-897.

Craig J. R., Vaughan, D. J, Skinner B. J., 2001. Resources of the Earth, 3rd Ed., Prentice Hall, Pearson Education, cop 2001, 520 p.

Craig, P. P., 2001. Energy limits on recycling, Ecological Economics, 36 (3), 373 384.

Crowson, P., 2012. Some observations on copper yields and ore grades, Resources Policy, 37 (1), 59-72. 
Dale, M., 2010. Global Energy Modeling: A Biophysical Approach (GEMBA). University of Canterbury, Christchurch, New Zealand.

Daly, H.E., 1985. The circular flow of exchange value and the linear throughput of matter-energy: a case of misplaced concreteness, Review of Social Economy, 43 (3), 279-297.

Elshkaki, A., Graedel, T. E., 2013. Dynamic analysis of the global metals flows and stocks in electricity generation technologies, Journal of Cleaner Production, 59, 260273.

Freise, J., 2011. The EROI of Conventional Canadian Natural Gas Production, Sustainability, 3, 2080-2104.

Gagnon, L., Belanger, C., Uchiyama, Y., 2002. Life-cycle assessment of electricity generation options: The status of research in year 2001, Energy Policy, 30, 12671278.

Gagnon, N., Hall, C.A.S., Brinker, L., 2009. A preliminary investigation of the energy return on energy invested for global oil and gas extraction, Energies, 2, 490-503.

Georgescu-Roegen, N., 1971. The Entropy Law and the Economic Process, Harvard University Press, Cambridge, Massachusetts.

Goeller, H. E., Weinberg, A. M., 1978. The age of Substituability, The American Economic Review, 68 (6), 1-11.

Guilford, M.C., Hall, C.A.S., O’Connor, P., Cleveland, C.J., 2011. A new long-term assessment of energy return on investment (EROI) for U.S. oil and gas discovery and production, Sustainability, 3, 1866-1887.

Hall, C.A.S., 1972. Migration and metabolism in a temperate stream ecosystem, Ecology, 53 (4), 585-604. (Ph.D. Thesis, University of North Carolina, Chapel Hill, 1970)

Hall, C.A.S., Cleveland, C. J., Kaufmann, R. K., 1986. Energy and Resource Quality: The Ecology of the Economic Process, Wiley Interscience, New York.

Hall, C.A.S., Day, J.W., 2009. Revisiting the limits to growth after peak oil, American Scientist, 97, 230-237.

Hall, C.A.S., Klitgaard, K.A., 2012. Energy and the Wealth of Nations: Understanding the Biophysical Economy, Springer, 407 pp., ISBN 978-1-4419-93977.

Hall, C.A.S., Lambert, J.G., Balogh, S., 2014. EROI of different fuels and the implications for society, Energy Policy, 64, 141-152.

Halloran, D., 2008a. Appendix H: Geothermal Energy Summary. The Oil Drum, 2008; Available online: http://www.theoildrum.com/node/3949 (accessed on 26 June 2013). 
Halloran, D., 2008b. Appendix I: Wave Energy: Potential, EROI, and Social and Environmental Impacts. The Oil Drum, 2008; Available online: http://www.theoildrum.com/node/3949 (accessed on 26 June 2013).

Harmsen, J. H. M., Roes, A. L., Patel, M. K., 2013. The impact of copper scarcity on the efficiency of 2050 global renewable energy scenarios, Energy, 50, 62-73.

Heun, M., De Wit, M., 2012. Energy return on (energy) invested (EROI), oil prices, and energy transitions, Energy Policy, 40, 147-158.

Hu, Y., Feng, L., Hall, C.C., Tian, D., 2011. Analysis of the Energy Return on Investment (EROI) of the Huge Daqing Oil Field in China, Sustainability, 3, 23232338.

International Energy Agency, 2014. Statistics: Energy Balance Flows, consultable à la page suivante: http://www.iea.org/Sankey/index.html.

King, C. W., Hall, C. A. S., (2011). Relating Financial and Energy Return on Investment, Sustainability, 3, 1810-1832.

Kleijn, R., Van der Voet, E., 2010. Resource constraints in a hydrogen economy based on renewable energy sources: An exploration, Renewable and Sustainable Energy Reviews, 14 (9), 2784-2795.

Kleijn, R., Van der Voet, E., Kramer, G. J., Van Oers, L., Van der Giesen, C., 2011. Metal requirements of low-carbon power generation, Energy, 36 (9), 5640-5648.

Kreith, F., Krumdieck, S. Principles of Sustainable Energy Systems, CRC Press, August $19^{\text {th }} 2013,790$ pp.

Kubiszewski, I., Cleveland, C.J., Endres, P.K., 2010. Meta-analysis of net energy return for wind power systems, Renewable Energy, 35, 218-225.

Lambert, J., Hall, C., Balogh, S., Poisson, A., Gupta, A., 2012. EROI of Global Energy Resources: Preliminary Status and Trends, Report 1 of 2. UK-DFID 59717, 2 November 2012.

Lund, P. D., 2007. Upfront resource requirements for large-scale exploitation schemes of new renewable technologies, Renewable Energy, 32, 442-458.

Memary, R., Giurco, D., Mudd, G., Mason, L., 2012. Life cycle assessment: a timeseries analysis of copper Journal of Cleaner Production, 33, 97-108.

Messner, F., 2002. Material substitution and path dependence: empirical evidence on the substitution of copper for aluminum, Ecological Economics, 42 (1-2), 259-271.

Moerschbaecher, M., and Day Jr., J.W., 2011. Ultra-Deepwater Gulf of Mexico Oil and Gas: Energy Return on Financial Investment and a Preliminary Assessment of Energy Return on Energy Investment, Sustainability, 3, 2009-2026.

Moss, R.L., Tzimas, E., Kara, H., Willis, P., Kooroshy, J., 2013. The potential risks from metals bottlenecks to the deployment of Strategic Energy Technologies, Energy Policy, 35, 556-564. 
Mudd, G., 2010. The Environmental sustainability of mining in Australia: key megatrends and looming constraints, Resources Policy, 35 (2), 98-115.

Mudd, G., Diesendorf, M., 2008. Sustainability of Uranium Mining and Milling: Toward Quantifying Resources and Eco-Efficiency, Environmental Science et Technology, 2008, 42 (7), 2624-2630.

Norgate, T., Haque, N., 2010. Energy and greenhouse gas impacts of mining and mineral processing operations, Journal of Cleaner Production, 18, 266-274.

Norgate, T., Jahanshahi, S., 2010. Low grade ores - Smelt, leach or concentrate?, Minerals Engineering, 23 (2), 65-73.

Norgate, T., Jahanshahi, S., 2011. Reducing the greenhouse gas footprint of primary metal production: Where should the focus be?, Minerals Engineering, 24 (14), 15631570 .

Northey, S., Haque, N., Mudd, G., 2013. Using sustainability reporting to assess the environmental footprint of copper mining, Journal of Cleaner Production, 40, 118128.

Odum, H. T., 1973. Energy, Ecology, and Economics, AMBIO, 2 (6), 220-227.

Odum, H.T., 1971. Environment, Power, and Society. Wiley-Interscience, New York, $331 \mathrm{pp}$.

Page, N. J., Creasey, S. C., 1975. Ore grade, metal production, and energy, Geological Survey Research Journal, 3 (1), 9-13.

Pihl, E., Kushnir, D., Sandén, B., Johnsson, F., 2012. Material constraints for concentrating solar thermal power, Energy, 44, 944-954.

Pimentel, D., Patzek, T., 2006. Editorial: Green plants, fossil fuels, and now biofuels, Bioscience, 56, 875.

Pimentel, D.; Patzek, T., 2005. Ethanol Production Using Corn, Switchgrass, and Wood; Biodiesel Production Using Soybean and Sunflower. Natural Resources Research, 14, 65-76.

Rankin, W. J., 2011. Minerals, Metals and Sustainability: Meeting Future Material Needs, Edition CRC Press Inc, 440p.

Raugei, M., Fulluna-i-Palmer, P., Fthenakis, V. The energy return on energy investment (EROI) of photovoltaics: Methodology and comparisons with fossil fuel life cycles. Energy Policy 45 (2012) 576-582.

Ruth, M., 1995. Information, order and knowledge in economic and ecological systems: implications for material and energy use, Ecological Economics, 13 (2), 99114.

Schodde, R.C., 2010. The key drivers behind resource growth: an analysis of the copper industry over the last 100 years, Presentation to the Mineral Economics \& Management Society (MEMS) session at the 2010 SME Annual Conference, Phoenix, Arizona March 2010. 
Skinner, B. J., 1976. A Second Iron Age Ahead?, American Scientist, 64 (3), 258269.

Steen, B., Borg, G., 2002. An Estimation of the cost of sustainable production of metal concentrates from the earth's crust, Ecological Economics, 42 (3), 401-413.

Stern, D. I., Kander, A., 2012. The Role of Energy in the Industrial Revolution and Modern Economic Growth, Energy Journal, 33 (3), 125-152.

Tharumarajah, A., and Koltun, P., 2011. Cradle To Gate Assessment Of Environmental Impact Of Rare Earth Metals, 7th Australian Conference on Life Cycle Assessment, Melbourne, Vic, Australia, 9-10 March 2011, 5p.

UKERC, 2013a. Materials Availability: Potential constraints to the future low-carbon economy, Working Paper I: Thin Film Photovoltaics, April 2011: UKERC/WP/TPA/2011/002, 88p.

UKERC, 2013b. Materials Availability: Potential constraints to the future low-carbon economy, Working Paper III: Batteries, Magnets and Materials, February 2013: UKERC/WP/TPA/2013/003, 102p.

UNEP, 2013. Environmental Risks and Challenges of Anthropogenic Metals Flows and Cycles, A Report of the Working Group on the Global Metal Flows to the International Resource Panel: Van der Voet, E., Salminen, R., Eckelman, M., Mudd, G., Norgate, T., Hischier, R.

USGS, 2012. Commodity Statistics and Information, retrieved from: http://minerals.usgs.gov/minerals/pubs/commodity/.

Valero, A., Botero., E., 2002. Exergetic Evaluation of Natural Mineral Capital (2): Application of the Methodology to Current World Reserves In: Proceedings of ECOS 2002. 15th International Conference on Efficiency, Costs, Optimization, Simulation and Environmental Impact of Energy Systems. TU-Berlin, Berlin, Germany, pp. 6268.

Vidal, O., Goffé, B., Arndt; N., 2013. Metals for a low-carbon society, Nature Geoscience, 6, 894-896.

Weißbach, D., G. Ruprecht, A. Huke, K. Czerski, S. Gottlieb, A. Hussein. Energy intensities, EROIs (energy returned on invested), and energy payback times of electricity generating power plants. Energy 52 (2013) 210-221.

Yang, C-J., 2009. An impending platinum crisis and its implications for the future of the automobile, Energy Policy, 37, 1805-1808. 